\title{
Surface Currents and Winds at the Delaware Bay Mouth
}

P. A. Muscarella, N. P. Barton, B. L. Lipphardt, D.

E. Veron, K. C. Wong, A. D. Kirwan

April 12, 2011

Continental Shelf Research 
This document was prepared as an account of work sponsored by an agency of the United States government. Neither the United States government nor Lawrence Livermore National Security, LLC, nor any of their employees makes any warranty, expressed or implied, or assumes any legal liability or responsibility for the accuracy, completeness, or usefulness of any information, apparatus, product, or process disclosed, or represents that its use would not infringe privately owned rights. Reference herein to any specific commercial product, process, or service by trade name, trademark, manufacturer, or otherwise does not necessarily constitute or imply its endorsement, recommendation, or favoring by the United States government or Lawrence Livermore National Security, LLC. The views and opinions of authors expressed herein do not necessarily state or reflect those of the United States government or Lawrence Livermore National Security, LLC, and shall not be used for advertising or product endorsement purposes. 


\title{
Surface Currents and Winds at the Delaware Bay Mouth
}

\author{
P. A. Muscarella ${ }^{1}$ \\ N. P. Barton ${ }^{2}$ \\ B. L. Lipphardt, Jr. ${ }^{1}$ \\ D. E. Veron ${ }^{1}$ \\ K. C. Wong ${ }^{1}$ \\ A. D. Kirwan, Jr. ${ }^{1}$ \\ ${ }^{1}$ College of Earth, Ocean, and Environment, University of Delaware, \\ Newark, DE, 19716, USA \\ ${ }^{2}$ Program for Climate Model Diagnosis and Intercomparison, Lawrence Livermore National Laboratory, \\ Livermore, CA, 94551, USA
}

April 5, 2011

Submitted to Continental Shelf Research 
Abstract

Knowledge of the circulation of estuaries and adjacent shelf waters has relied on hydrographic measurements, moorings, and local wind observations usually removed from the region of interest. Although these observations are certainly sufficient to identify major characteristics, they lack both spatial resolution and temporal coverage. High resolution synoptic observations are required to identify important coastal processes at smaller scales. Long observation periods are needed to properly sample low-frequency processes that may also be important. The introduction of high-frequency (HF) radar measurements and regional wind models for coastal studies is changing this situation. Here we analyze synoptic, high-resolution surface winds and currents in the Delaware Bay mouth over an eight-month period (October 2007 through May 2008). The surface currents were measured by two high-frequency radars while the surface winds were extracted from a data-assimilating regional wind model. To illustrate the utility of these monitoring tools we focus on two 45-day periods which previously were shown to present contrasting pictures of the circulation. One, the low-outflow period is from 1 October through 14 November 2007; the other is the high-outflow period from 3 March through 16 April 2008. The large-scale characteristics noted by previous workers are clearly corroborated. Specifically the M2 tide dominates the surface currents, and the Delaware Bay outflow plume is clearly evident in the low frequency currents. Several new aspects of the surface circulation were also identified. These include a map of the spatial variability of the M2 tide (validating an earlier model study), persistent low-frequency cross-mouth flow, and a rapid response of the surface currents to a changing wind field. However, strong wind episodes did not persist long enough to set up a sustained Ekman response. 


\section{Introduction}

The Delaware Bay estuary is one of the largest along the U.S. east coast. It is $45 \mathrm{~km}$ wide at its widest point and extends approximately $210 \mathrm{~km}$ from the head of the Delaware River to the bay mouth. The mouth is $18 \mathrm{~km}$ wide from Cape Henlopen, Delaware to Cape May, New Jersey. The bay's mean depth is 7 $\mathrm{m}$ with a maximum depth of approximately $30 \mathrm{~m}$ in a deep channel at the southern side of the bay mouth. Over eight million people live within the Delaware River watershed. The bay is also a major shipping hub, with 4200 commercial ship visits to 9 ports in three states each year. Most importantly for our purposes, it is responsible for a significant fraction of the transport of freshwater and associated terrestrially-derived material to the ocean along the Atlantic seaboard as well as larval and sediment. As noted by Brink et al. (1992), quantifying this transport is one of the major goals of oceanography.

Previous work in Delaware Bay and adjacent coastal waters identified three dominant forcing mechanisms typically associated with estuarine-ocean exchange: tides, buoyancy-driven flow, and winds. From 53 current meter records, Münchow et al. (1992) reported that the M2 tide explains about $90 \%$ of the tidal current kinetic energy variance. Their M2 tidal ellipses showed significant spatial variability near the bay mouth with decreasing major axes and reduced ellipticity moving seaward. They also estimated the M2 volume flow through the bay mouth as approximately $1.5 \times 10^{5} \mathrm{~m}^{3} \mathrm{~s}^{-1}$. The resulting ratio of M2 volume flow to average freshwater inflow is approximately 260, suggesting minimal stratification throughout most of the year. Whitney and Garvine (2008) codified these results in a model for estimating tidal current amplitudes.

Pape and Garvine (1982) used surface and subsurface drifters near the Delaware Bay mouth to document a classical, two-layer estuarine flow (near-surface outflow and inflow near the bottom). Later, Garvine (1991) found a strong outflow plume along the southern bay mouth and some evidence of cross-mouth flow using current meters and hydrography. Later efforts reported by Münchow (1992) and Münchow and Garvine (1993), Wong and Münchow (1995), and Avicola and Huq (2002) focused on plume dynamics. Whitney (2003) provides an excellent review of this work.

Understanding the effects of winds on Delaware Bay subtidal circulation has been guided by the early analysis of Garvine (1985). He used land stations in New Jersey to develop a model that partitioned the ocean response into locally and remotely forced components. The local response is due to the direct influence of local wind stress on the estuary, while the remote response is driven by sea level changes set up by Ekman transport due to large-scale (non-local) atmospheric processes. In Delaware Bay, the remote response dominates and generally opposes the local response. This analysis was extended by Münchow and Garvine (1993), Wong (1999), and Janzen (2000).

Whitney (2003) made an ambitious attempt to model the circulation in Delaware Bay and its exchange with the coastal ocean, accounting for tidal and buoyant forcing, and the influence of temporal variations of a spatially uniform wind field. That effort was extended by Whitney and Garvine (2006) who compared model simulations with observations from the spring of 1993 and 1994. The observations included salinity climatology, freshwater outflow from stream gauges, hydrographic observations of the salinity in the plume 
and coastal current, and some surface drifter data.

The majority of published work related to Delaware Bay circulation was completed over the last three decades and based solely on relatively short ocean time series measurements from sparse, fixed locations. Much of this work also used wind measurements, mostly over land, supplemented by measurements from a few offshore buoys near the bay, but outside its mouth. The historically sparse, intermittent ocean sampling is typical of virtually all coastal zones, and, for Delaware Bay, was sufficient to provide a consistent general picture of the ocean circulation and the role of near-surface winds. However, these historical measurements were poorly resolved in space and could only account for processes occurring when the measurements were made. Consequently they are insufficient for addressing questions related to the scales of spatial and temporal variability.

Here we provide synoptic descriptions of the variability of surface currents and $10 \mathrm{~m}$ winds from 1 October 2007 through 31 May 2008. The surface currents were measured using two high-frequency (HF) radars at the Delaware Bay mouth on a grid with $1.5 \mathrm{~km}$ resolution. Near-surface winds were obtained from the Weather Research and Forecasting (WRF) model, which uses advanced parameterizations to calculate local wind fields onto a fine scale (one kilometer) grid from the North American Model(NAM) (http://dss.ucar.edu/datasets/ds609.2). This dataset was downloaded from National Center for Atmospheric Research's (NCAR) Computational and Information Systems Laboratory (CISL). Both the HF radar measurements and WRF wind fields were available hourly and provided temporal and spatial resolution unavailable to earlier workers.

Surface currents from HF radar were measured nearly continuously over the eight-month study period, except for a 17-day gap in December 2007 due to a power outage. Since these measurements were reported hourly, they allow the variability of surface currents at tidal and subtidal time scales to be assessed. Tidal fits were computed for the entire eight-month record, including the December 2007 gap. For comparisons between winds and surface currents, we focused on two periods of contrasting Delaware River outflow conditions: a low outflow period from 1 October to 14 November 2007 and a high outflow period from 3 March to 16 April 2008. The region around the Delaware Bay mouth and example model winds and HF radar measured surface currents for 1 October 2007 are shown in Figure 1. In Figure 1a, every third wind vector from the inner model nest (see section $2 \mathrm{~b}$ ) is shown, and the green box shows the limits of the geographic region shown in Figure 1b.

Since few comparisons between long time-series of HF radar measured surface currents and historical observations have been made in well-studied coastal areas, the analysis presented here serves two purposes. First, the general agreement we find between synoptic surface current patterns and known aspects of the surface estuarine circulation from historical studies gives added confidence to HF radar measurements. These measurements are difficult to benchmark, as they are averaged over time and space scales that are significantly larger than those for other point measurements. Second, the synopticity of the measured surface currents and their continuity over an eight-month period augments the traditional observational strategy 
that relies on sparse arrays of point measurements over relatively short time periods. Synoptic measurements support a detailed assessment of spatial variability, and a long, continuous record captures low-frequency characteristics. In particular, a persistent cross-mouth flow is identified in an undersampled region of the bay mouth.

Since winds at the Delaware Bay mouth vary substantially in both space and time, the lack of a synoptic wind record has limited the ability of previous workers to explore the relationship between winds and surface currents at the mouth. Here, the comparisons between synoptic model winds and measured surface currents represent a first step toward understanding the role of spatially varying winds on the surface circulation. Since the winds are most often episodic, the wind-driven circulation cannot be interpreted under the assumption of steady-state. A detailed description of the wind-driven circulation, then, remains a challenging problem.

The remainder of this paper is organized as follows. The next section describes the synoptic data used for this analysis: HF radar measured surface currents and near-surface winds from the WRF model. Section 3 presents the results of an eight-month tidal analysis of the surface currents at the bay mouth. In section 4, low-frequency surface currents during low and high outflow periods are described, and maps of their correlations with model near-surface winds are presented. Section 5 discusses the results and our conclusions. 


\section{Synoptic datasets}

\section{a. Surface currents}

Over the last two decades, oceanographers have routinely mapped surface currents by measuring Doppler shifted backscatter using HF radars. See Paduan and Graber (1997) for an accessible discussion of HF radar theory. These measurements have significant advantages over traditional measurements from moorings and ship mounted acoustic Doppler current profilers (ADCPs) as they provide high-resolution synoptic coverage on hourly time scales and are amenable to routine monitoring. Their chief limitation is that they only measure currents near the ocean surface.

As HF radar has emerged as a unique sensor for synoptic current mapping, a number of studies have assessed these measurements using ADCPs, current meters, and Lagrangian drifters (Chapman and Graber 1997; Chapman et al., 1997; Graber et al., 1997; Kohut et al., 2006; Paduan et al., 2006; Ohlmann et al., 2007, and others). Most recent assessments of HF radar vs. point measurements report root mean squared (RMS) differences of 7-19 $\mathrm{cm} \mathrm{s}^{-1}$. Ohlmann et al. (2007) reported differences of $3-5 \mathrm{~cm} \mathrm{~s}^{-1}$ between HF radar measurements and velocities derived from clusters of drifter trajectories in the Santa Barbara Channel. They also present an excellent summary of published HF radar assessment studies and a detailed discussion of the possible sources of differences between HF radar measurements and those of other sensors. Since HF radar measurements are averaged over time scales of 1-3 hours and space scales of 1-10 km (ocean areas of 1-100 $\mathrm{km}^{2}$ ), the measurements include contributions from real ocean variability over these time and space scales. As a result, comparisons with independent point measurements (from ADCPs, current meters, or drifter trajectories) must be interpreted with care, since these sensors average over much smaller space and time scales.

More relevant to this study, Skarke et al. (2008) compared HF radar measurements with near-surface velocities from a bottom mounted ADCP during October-November 2007 and found complex correlation amplitudes greater than 0.9 with mean direction differences of 0.3 to 0.6 degrees just south of the Delaware Bay mouth near the edge of the analysis region.

As oceanographers have gained confidence in the reliability of HF radars, a significant number of studies based on these measurements have emerged over the last decade. Shay et al. (2001) gave a detailed analysis of the M2 tide at the Chesapeake Bay mouth. Beckenbach and Washburn (2004) used three years of HF radar measurements to describe intermittent low-frequency waves propagating through the Santa Barbara Channel. In Monterey Bay, Lagrangian analyses of HF radar measurements have been used to study surface transport (Lipphardt et al., 2006; Coulliette et al., 2007).

The surface current measurements used here come from two standard-range, $25 \mathrm{MHz}$ radars. These radars are both SeaSonde-type Coastal Ocean Dynamics Applications Radars (CODAR). The southern site is located at Cape Henlopen, DE while the northern site is on the southern tip of Cape May, NJ (see Figure 1). Since a single radar measures only the surface velocity component along a radial originating from the 
antenna, total vector current maps require a minimum of two radars. Moreover, the velocity component perpendicular to the baseline between two antennas cannot be resolved. For this reason, surface currents near the baseline between the two Delaware Bay radars are not used here.

At each radar site, hourly radial velocities were measured on a polar coordinate grid centered on the antenna location, with an azimuthal cell spacing of five degrees and a range cell spacing of $1.5 \mathrm{~km}$. Radial velocities from the two sites were objectively mapped using a least-squares technique (Lipa and Barrick, 1983) to produce hourly maps of total velocities on a uniform grid with $1.5 \mathrm{~km}$ resolution. For this leastsquares technique, all radial velocities from both sites that were within $3 \mathrm{~km}$ of each totals grid point were combined using unweighted least-squares to produce a single velocity estimate at the grid point.

SeaSonde-type HF radar receive antennas can be sensitive to distortion from nearby objects, and the accuracy of their measurements is most often improved by measuring the antennas response pattern (Paduan et al., 2006). The antenna patterns for the Cape May and Cape Henlopen sites were measured in September 2007 and found to be nearly ideal. However, when the measured pattern was used to reprocess data at the Cape Henlopen site, azimuthal gaps occurred, resulting in significant data loss. Since the cause of this spokiness in azimuthal coverage is due to small scale roughness in the measured antenna pattern, ideal antenna patterns were used for all HF radar measurements described here.

Environmental factors influence the spatial extent of the total velocity measurement footprint over time, and occasional gaps within the footprint do occur. See Paduan and Rosenfeld (1996) for a detailed explanation. To minimize the effects of temporal gaps, we restricted our analysis to grid locations that had at least $80 \%$ coverage in time over the analysis period. An example hourly HF radar surface current map is shown in Figure 1b. Several gaps are seen along the outer edge of the measurement footprint. Figure 2 shows the percent coverage in time for the radar grid, the grid points with at least $80 \%$ coverage in time, and the mean velocities at these locations for the entire analysis period. Note also that an equipment failure from 2200 UT 3 December to 1300 UT 20 December 2007 prevented any HF radar measurements during that period.

\section{b. Surface winds}

For synoptic winds over the Delaware Bay we used the Advanced Research version of the Weather Research and Forecasting (WRF) (http://wrf-model.org) model version 2.2 (Skamarock et al., 2007; Wang et al., 2007). WRF is a numerical weather prediction system designed to serve both operational forecasting and atmospheric research needs at scales from $300 \mathrm{~m}$ to $1000 \mathrm{~km}$. This regional-scale atmospheric model was jointly developed by many weather forecasting and atmospheric climate modeling communities.

WRF features modern radiation and land surface parameterizations as well as three-dimensional data assimilation. In this study, the Rapid Radiative Transfer Model (RRTM) longwave radiation parameterization (Mlawer et al., 1997) and short wave radiation parameterization (Dudhia, 1989) are used to represent atmospheric radiative transfer. The planetary boundary layer (PBL) and turbulence processes are represented by the Mellor-Yamada-Janjic Yonsei (MJY) University PBL scheme (Hong et al., 2006). The tendencies 
calculated at each location by the MYJ scheme depend only on the local properties of the flow. This PBL scheme has been shown to produce more accurate surface winds over the ocean near Korea and Japan relative to other PBL parameterizations in WRF (Kwun et al. 2009).

WRF also uses a surface layer parameterization to calculate friction velocities and exchange coefficients for surface heat and moisture fluxes. The layer next to the surface is a traditional Monin-Obukhov surface layer. Between this layer and the first PBL layer is a surface layer parameterization that uses National Centers for Environmental Prediction (NCEP) Eta similarity theory scheme (Janjic 1996, 2002). Land surface processes are represented by the multilayer Noah surface model (Pan and Mahrt, 1987; Chen and Dudhia, 2001; Ek et al., 2003; Holt et al., 2006) to provide heat and moisture fluxes to the PBL scheme.

Regional weather forecast models have been used to investigate the influence of coastal winds on surface current for at least 40 years (McPherson, 1970; Ohashi and Kid, 2002; Thompson et al., 2007). Regional atmospheric models have also been used to investigate the influence of urban surfaces, or modification of land surfaces, on weather patterns (Kabat, 2004), and climate (Pielke, 2001). WRF, in particular, was recently used to investigate sea breeze effects and the atmospheric impact on $\mathrm{CO}_{2}$ fluxes (Ahmadov et al., 2007), the transport of ozone (Darby et al., 2007), and as a model for low-level meridional circulation (Nolan et al., 2007).

Correctly simulating low-level winds along coastlines is one of the challenges of current mesoscale and regional-scale atmospheric modeling. Consequently, a coastal mesoscale atmospheric model must be carefully assessed. This can be especially challenging for wind-current interaction studies, since wind observations, while typically numerous over land, are sparse over water. Darby et al.(2007) used WRF and Penn State's fifth generation meso-scale model (MM5) to look at the impact of sea breeze circulation on ozone transport. Over several days, WRF predicted the onset of the sea breeze slightly early or on time when compared with lidar observations. However, both WRF and MM5 wind speeds were high relative to observations, and more significantly, both models demonstrated reduced predictive skill when local-scale meteorological events were dominant. During the Carbon Europe Regional Experiment Study (CERES), comparisons between WRF wind profiles and radiosonde launches over southern France showed that the model accurately predicted wind speed and direction in the mornings, with some disagreement in direction in the afternoon when local forcing dominated (Ahmadov et al., 2007).

Here, WRF was forced with coarse-scale information from NCEP's North American Model (NAM) which has a spatial resolution of $40 \mathrm{~km}$ and a temporal resolution of six hours. Our Delaware Bay simulations use three nested domains with spatial resolutions of $9 \mathrm{~km}$ (outer nest), $3 \mathrm{~km}$ (middle nest), and $1 \mathrm{~km}$ (inner nest). The spatial resolution of the land surface is 30 seconds for the two inner nests. Figure 3 shows the area covered by each of the two inner nests. The outer nest (extending from south of Cape Hatteras, NC northward to Long Island, NY) is sized to capture synoptic storms that may affect Delaware Bay. The middle nest (Figure 3, region 2) covers the entire Delaware Bay, and the inner nest (Figure 3, region 3) includes the entire HF radar measurement footprint. Overlapping five-day WRF simulations were computed for both 
the low and high outflow periods. The first day of each five-day run was discarded as spin-up and the start of each run overlapped the previous run by one day. Winds at $10 \mathrm{~m}$ were archived hourly. Figure 1a shows example $10 \mathrm{~m}$ wind vectors for $1000 \mathrm{UT}, 1$ October 2007, with every third wind vector shown, for clarity.

To assess the accuracy of the $10 \mathrm{~m}$ WRF winds used here, we compared them with observed winds (corrected to a height of $10 \mathrm{~m}$ ) from eight stations around Delaware Bay during both the low and high outflow periods. Six of these stations were on or very near land (shown as numbered white circles in Figure 3). For these six stations, comparisons were made with the nearest WRF model grid location, typically less than $0.5 \mathrm{~km}$ away, except for station 6 , which is $1.5 \mathrm{~km}$ away from the nearest model grid location (in the WRF middle nest). The remaining two stations were over water, and the closest two stations to our study region (Brandywine Light and NOAA buoy 44009, shown as red circles in Figure 3). For these two stations, since the model winds are more spatially coherent over water, they were linearly interpolated in space to the station location. At all stations, observed winds were linearly interpolated to the nearest hour to match the WRF archiving scheme.

At each of the eight stations, complex correlation magnitude $\left(\sigma_{m a g}\right)$ and meen veering angle $\left(\sigma_{\text {phase }}\right)$ were computed (Kundu, 1976). $\sigma_{\text {phase }}$ is a measure of the average direction error (in degrees) between two vector time series, with negative values indicating model winds to the right of observed winds. RMS differences between observed and modeled wind components at $10 \mathrm{~m}\left(\Delta u_{r m s}, \Delta v_{r m s}\right)$ were also computed, as well as the RMS value of the observed wind magnitude $\left(|\vec{v}|_{r m s}\right)$. Table 1 shows the comparison statistics for each station during both the low and high outflow periods. Units for all RMS values are $\mathrm{m} \mathrm{s}^{-1}$. Note that no observations were available at Brandywine Light for the high outflow period.

For the two stations over water (Brandywine and Buoy 44009), all $\sigma_{m a g}$ are 0.88 or greater, and all $\sigma_{\text {phase }}$ values are less than $8^{\circ}$. All $\Delta u_{r m s}$ and $\Delta v_{r m s}$ values are roughly $2.5 \mathrm{~m} \mathrm{~s}^{-1}$, with $|\vec{v}|_{r m s}$ values of $7-8$ $\mathrm{m} \mathrm{s}^{-1}$. At the six stations on or near land (stations 1-6), Table 1 shows $\sigma_{\text {mag }}$ range from $0.75-0.87$, with slightly higher correlations during the high outflow period. All $\sigma_{\text {phase }}$ values at stations $1-6$ are less than $20^{\circ}$, except for station 1 during the high outflow period, when $\sigma_{\text {phase }}$ increased to almost $22^{\circ}$. $|\vec{v}|_{r m s}$ values at stations 1-6 ranged from 2.64-6.94 $\mathrm{m} \mathrm{s}^{-1}$, with $\left(\Delta u_{r m s}, \Delta v_{r m s}\right)$ values typically one-half to two-thirds of the $|\vec{v}|_{r m s}$ values.

Coastal wind modeling is a challenging problem, particularly in geographic regions like Delaware Bay, where the winds are typically weak and variable. We are encouraged by the vector correlations shown in Table 1, and we view the RMS differences as acceptable measures of model skill for our purposes, since we focus primarily on vector correlations between model wind velocities and surface currents. We found that the 40-hour low-pass filter (applied to both winds and surface currents prior to computing vector correlations) reduced the RMS differences between observed and modeled winds at all stations by roughly $0.5 \mathrm{~m} \mathrm{~s}^{-1}$. We also expect vector correlations computed over 45-day periods to be relatively insensitive to the moderate amount of model uncertainty that remains. 


\section{Tides at the Delaware Bay Mouth}

Münchow et al. (1992) used current meter records at various depths from 31 moorings to show that the M2 tide constituent was the dominant component on the coastal region adjacent to the Delaware Bay mouth. However, only nine of their moorings were in the immediate vicinity of our analysis region, four along the line across the bay mouth, and five southeast of our radar footprint (Figure 4, black ellipses). Along the bay mouth, their M2 tide ellipses were nearly rectilinear and roughly perpendicular to the line across the mouth. Offshore, M2 tidal current magnitudes decreased by at least a factor of two. The sparseness of these observations motivated Whitney and Garvine (2008) to study the spatial variability of the M2 tides outside the bay mouth with a numerical model. Their M2 tidal currents, although broadly consistent with the Münchow et al. (1992) analysis, could not be assessed with independent observations. Here we examine the spatial variability of the M2 tidal currents using HF radar measurements. We show that the Whitney and Garvine (2008) results agree remarkably well with the radar observations.

Tide fits from time series of HF radar surface velocities were computed using the Matlab T_TIDE toolbox (Pawlowicz et al., 2002), which fits multiple harmonics to vector time series that may include temporal gaps. A total of 45 astronomical and 101 shallow-water constituents are available. Signal to noise ratios $(S N R)$ are estimated for each constituent using a nonlinear parametric bootstrap technique with a white noise assumption. We followed Pawlowicz et al. (2002) recommendation and used a minimum $S N R$ value of two as a measure of a statistically significant fit. As a measure of tidal energy, we define a tidal ellipse magnitude $\mathcal{M}$ as the square root of the sum of the squares of the major $\left(r_{a}\right)$ and minor $\left(r_{b}\right)$ tidal ellipse axes:

$$
\mathcal{M}=\sqrt{r_{a}^{2}+r_{b}^{2}}
$$

For the eight-month analysis period, tidal velocity fits were computed at 250 grid locations with at least $80 \%$ temporal coverage (see Figure 2). We explored the relative importance of all resolved tidal constituents by examining fits using a set of constituents selected using T_TIDE's objective criteria. For most grid locations, five constituents (M2, N2, S2, K1, and O1) were found to be the most energetic (largest $\mathcal{M}$ values). In many cases, these five consituents were also the only ones with statistically significant fits $(S N R \geq 2)$. We then computed a second set of tide fits at each grid location using only these five constituents.

Table 2 shows $\mathcal{M}$ and $S N R$ statistics (minimum, maximum, mean, and standard deviation) for the five-constituent tide fits at the 250 grid locations shown in Figure 2. All minimum $S N R$ values in Table 1 are greater than two, and mean $S N R$ values were approximately 20 or greater. Mean $\mathcal{M}$ values for N2 and S2 were about 8 , roughly one-fifth of the M2 value. Mean $\mathcal{M}$ values for the two diurnal constituents were about 4, roughly one-tenth of the M2 value.

M2 tidal ellipses are shown in red in Figure 4. For clarity only every second ellipse is shown. Ellipses from the Münchow et al. (1992) analysis are also shown (in black). The overall agreement between the M2 ellipses from two data sets shown in Figure 4 is excellent, both showing rectilinear ellipses aligned with the 
local bathymetry at the bay mouth.

Five of the Münchow et al. (1992) moorings were seaward of the radar footprint, to the southeast. Of the four Münchow et al. (1992) moorings near the bay mouth, only one was within the radar footprint, near the southern edge of the bay mouth. At this mooring location, Münchow et al. (1992) reported M2 $\left(r_{a}, r_{b}\right)$ values of $(94.3,7.5) \mathrm{cm} \mathrm{s}^{-1}$, with the ellipse oriented at an angle of $127.0^{\circ}$ with respect to east. These values agree very well with those computed at the nearest radar grid point (160 meters away): $\left(r_{a}, r_{b}\right)=(83.5$, 11.5) $\mathrm{cm} \mathrm{s}^{-1}$, with an ellipse orientation angle of $125.9^{\circ}$.

Figure 4 shows that the largest $\mathcal{M}$ values occur in the deep channel at the southern side of the bay mouth. M2 ellipses from the radar measurements show decreasing $\mathcal{M}$ values moving seaward, consistent with the smaller M2 current magnitudes at the five offshore Münchow et al. (1992) sites, and also consistent with the theoretical and model profiles shown in Figure 6 of Whitney and Garvine (2008).

M2 ellipses computed from the radar measurements (Figure 4) provide an important validation of the depth-averaged model M2 tidal current amplitudes reported by Whitney and Garvine (2008). Differences between M2 $r_{a}$ computed from the radar measurements and interpolated, depth-averaged values from the Whitney and Garvine (2008) model are shown in Figure 5. The model data used to compute these differences was provided by M. Whitney. Figure 5 shows that, except for radar grid points close to the bay mouth, the magnitudes of M2 $r_{a}$ differences were typically less than $10 \mathrm{~cm} \mathrm{~s}^{-1}$. Since typical M2 current amplitudes are $50-80 \mathrm{~cm} \mathrm{~s}^{-1}$ within the radar footprint, these differences represent uncertainties of $20 \%$ or less. Note also that the model $r_{a}$ values are depth-averaged, and likely underestimate the true near-surface values.

The $r_{a}$ differences shown in Figure 5 are larger near the bay mouth, with the largest differences occuring in the immediate vicinity of the Cape May peninsula. This is not suprising, since the bottom topography in that area is quite rugged, with water depths varying from one to ten meters over distances of less than one kilometer. In the model, this bottom bathymetry is smoothed, and locations with depths less than 1.5 meters are considered as land. In addition, radar measurement uncertainties are higher near the baseline between the two radars, which spans the bay mouth. Near the baseline, the look angles for the two radars are nearly parallel. When radial velocities become nearly parallel, geometric dilution of precision amplifies measurement uncertainties (Chapman et al., 1997).

Since Whitney and Garvine (2008) noted a steady decrease in model M2 $r_{a}$ moving offshore outside the bay mouth, we compared M2 $r_{a}$ values along a line originating midway across the bay mouth and extending offshore perpendicular to the bay mouth line for $25 \mathrm{~km}$ (black line shown in Figure 5). Profiles of $r_{a}$ interpolated at $1 \mathrm{~km}$ intervals along this line are shown in Figure 6 for the Whitney and Garvine (2008) model (in red) and for the HF radar tidal fits (in blue). No attempt was made to extrapolate radar $r_{a}$ values for locations outside the radar footprint. Figure 6 shows excellent agreement between the model and radar-derived $r_{a}$ profiles.

Tidal ellipses for the two other energetic semi-diurnal constituents (N2 and S2, not shown) were qualitatively very similar to the M2 ellipses and also agreed quite well with a single historical ellipse from Münchow 
et al. (1992). Diurnal (K1 and O1) ellipses (also not shown) were much less energetic, with typical $\mathcal{M}$ values about one-tenth of those for M2. K1 and O1 ellipses agreed well with those reported by Münchow et al. (1992) at one location within the radar footprint.

Figure 7 shows a map of the percent of the velocity variance explained by the five constituent tidal fits. The tides account for roughly $90 \%$ of the variance at the bay mouth. Typical maximum tidal currents are of the order of $100 \mathrm{~cm} \mathrm{~s}^{-1}$ in the deep channel at the southern bay mouth. However, this fraction drops to about $40 \%$ at the eastern edge of the radar footprint.

In a region like Delaware Bay, where an estuary meets the adjacent shelf, stratification during high runoff periods could conceivably amplify the nonlinear interactions among tide constituents, potentially causing a shift in tide fit parameters. We examined this possibility using monthly fits over our analysis period and found no detectable variation in tide fit parameters, even during the spring runoff in 2008. 


\section{Low Frequency Currents and Winds}

A lack of synoptic observations limited previous efforts to describe low-frequency variations of winds and currents at the Delaware Bay mouth. This obstacle is overcome with the high-resolution hourly HF radar surface currents and WRF modeled winds described here. We examined the low-frequency surface currents using a variety of techniques, including detiding, 40-hour low-pass filtering, and weekly and longer term averages at each radar grid point. Although the details vary somewhat depending on the type of average, the broad picture is remarkably consistent with earlier studies of Delaware Bay. Moreover, except for the high outflow period in March and April 2008, mean maps showed little variability from month to month.

The USGS Delaware River discharge record for Trenton, New Jersey provides a good measure of river flow, and is proportional to outflow at the bay mouth. Figure 8 shows the eight-month record of river flow at Trenton, with the low and high outflow periods highlighted in grey. Discharge during the high outflow period (March-April, 2008) was approximately 25 times higher than that for the low outflow (October-November, 2007) period.

Figure 9 shows 45-day mean surface currents for the low and high outflow periods. Currents at grid locations with at least $80 \%$ coverage over the 45 -day period are shown. The spatial coverage during the low-outflow period was better (reaching further offshore) when compared to the high-outflow period. Both periods show a clear outflow plume evident at the southern bay mouth (over the deep channel) and evidence of cross-mouth flow to the southwest. Maximum outflow plume currents are $10 \mathrm{~cm} \mathrm{~s}^{-1}$ higher during the high outflow period. Note that these maximum currents $\left(20-25 \mathrm{~cm} \mathrm{~s}^{-1}\right)$ are still only about $20 \%$ of the M2 tidal current amplitude. Current patterns at the eastern side of the footprint differ between the two periods: low-outflow period flow is predominantly to the east, and this flow veers to the south during the high-outflow period.

A southwesterly flow across the bay mouth was reported earlier by Garvine (1985) and Wong and MosesHall (1998). As their results were based on current meters at fixed locations, little attention has been paid to this feature. However, this feature appears in all the HF radar low-frequency currents. It is unusual in that the flow is oriented across the bathymetry at the mouth.

Figure 9 also shows color contours of the ratio of the mean current speed to the standard deviation magnitude for surface currents over the two analysis periods. Small values of this ratio (yellow-orange colors) show regions where velocity fluctuations are large compared to the mean speed, indicating that the mean flow is a poor indicator of "typical" flow conditions. During both periods, regions offshore of the bay mouth and northeast of the outflow plume have large velocity fluctuations compared to the mean.

It is challenging to assess the influence of local winds on surface currents in a coastal region when both winds and currents show marked variability. In Delaware Bay, diurnal variability due to seabreeze is significant during some periods, and tides are by far the most energetic component of the surface currents. Steady wind conditions rarely persist long enough to permit a simple Ekman analysis. Here we restrict our analysis to a single question: Once the energetic tides are removed, can a surface current response to local 
wind fluctuations be detected?

To address this question we computed complex correlations (Kundu, 1976) between surface currents and wind stress at $10 \mathrm{~m}$ from the WRF model for both the low and high outflow periods. The surface current and wind stress vector time series were each 40-hour low-pass filtered, and the model wind stresses were linearly interpolated to the radar grid. Figure 10 shows maps of the complex correlation magnitude $\left(\sigma_{m a g}\right)$ and mean veering angle $\left(\sigma_{\text {phase }}\right)$ for wind-current correlations during both analysis periods. Negative $\sigma_{\text {phase }}$ values indicate currents to the right of the winds.

The general correlation patterns in Figure 10 are quite similar between the two periods. The highest $\sigma_{m a g}$ values are near the center of the radar footprint. Near the bay mouth, where energetic mean flow to the southwest persists, $\sigma_{m a g}$ is reduced. At the southern side of the mouth, where energetic outflow persists, $\sigma_{m a g}$ is also reduced. The small, negative $\sigma_{\text {phase }}$ values near the center of the radar footprint indicate that the surface currents are slightly to the right of the wind. However in the outflow plume and along the northeast edge of the footprint, the low-frequency currents are to the left of the wind. These $\sigma_{\text {phase }}$ maps suggest that strong wind events do not last long enough to set up a significant Ekman response in the low-frequency circulation.

However, comparisons between wind stress and surface current time series show that surface currents do veer rapidly to the right in response to energetic wind events that persist for more than a few days. For example, Figures 11 (low outflow period) and 12 (high outflow period) show time series of WRF winds at $10 \mathrm{~m}$ and surface currents at point A, located in the center of the radar footprint (see Figure 1). Winds and surface currents have both been 40-hour low-pass filtered, and vectors are shown at six-hour intervals. Time series of the direction difference (currents minus winds) are also shown, with periods when the currents were to the right of the winds shown in red. The wind records are dominated by brief, energetic events that typically last no more than three days. The wind veering during these events indicates that they are most likely associated with passing weather systems, like storms. During energetic events, Figures 11 and 12 show that, while surface currents clearly veer rapidly to the right of the wind, the ocean response is simply not persistent enough to be detected through complex correlation analysis. 


\section{Discussion}

As noted previously, most of our knowledge of the Delaware Bay circulation has come from relatively short time series measurements from sparse arrays at fixed locations, or from hydrographic cruises of limited duration. In addition, the role of the surface wind on the circulation has been inferred from either land based observations or meteorological buoys well removed from the bay. These observations helped establish the broad characteristics of the surface circulation, such as the buoyant plume outflow and the role of remote wind forcing. However, the lack of synopticity and the limited time duration of such traditional observations greatly limit their ability to identify many dynamically significant flow characteristics. We addressed this issue using an eight-month record of synoptic surface currents from HF radar and near surface winds from WRF.

The analyses presented here used synoptic modeled winds and measured surface currents to build a more complete picture of the surface circulation at the Delaware Bay mouth. Previous studies, based on point measurements, have identified tides, local and remote wind forcing, and buoyant outflow as important forcing mechanisms that influence circulation.

Synoptic hourly HF radar surface currents, available nearly continuously over an eight-month period, allowed us to map the spatial variability of the dominant M2 tides and the percent of the total surface velocity variance explained by tidal fits using the five most energetic constituents. Near the bay mouth, M2 tidal ellipses from the radar measurements were highly elliptical and oriented perpendicular to the bay mouth (see Figure 4). Moving offshore, the ellipses became smaller and more circular. M2 tide ellipse parameters agree very well with analysis of historical point measurements (Münchow et al., 1992) and with results from the Whitney and Garvine (2008) numerical model (see Figures 5 and 6).

Our synoptic study of the M2 tide serves two purposes: it fills in "gaps" in the M2 tide picture based solely on historical point measurements, and it validates one numerical model study using previously unavailable synoptic velocities. The continuous eight-month record also allowed us to examine potential influences of stratification on the M2 tidal ellipses by comparing tidal fits from low and high outflow periods. Since the differences were negligible, we conclude that stratification effects are unimportant.

Continuous synoptic velocities were also used to assess how much of the total velocity variance is explained by the tides. Figure 7 shows that, near the bay mouth, tidal fits using the five most energetic constituents explain $80-90 \%$ of the velocity variance. Moving offshore, this fraction drops to 50-60\%. This analysis of velocity variance, however, ignores any spatial structure in the mean flow. To assess this, we computed mean surface velocities over two 45-day periods that contrast low and high freshwater outflow conditions. During both low and high outflows, two persistent low-frequency flow structures are apparent: the bay's energetic outflow plume at the southern bay mouth, and persistent, energetic cross-mouth flow toward the southwest. The outflow plume is well understood and well documented. While some published studies have hinted at possible cross-mouth flow, observational evidence has been ephemeral. Our results (Figure 9) clearly show that this is a persistent low-frequency flow feature, and it's structure is modulated to some 
extent by changing outflow conditions.

As noted above, there are no published direct comparisons of surface wind observations with surface currents in Delaware Bay. In prior studies, winds from land stations or a meteorological buoy located well outside the study area were used to establish a remote connection of winds on the surface circulation. Thus, very little is known about the spatial and temporal variability of surface winds and their relation to the circulation. We took a first step toward addressing this by correlating model winds with radar surface currents to assess the low frequency response. As the WRF model is data assimilating, we view these winds as dynamic interpolations of observations.

Seasonally persistent winds have been reported by Garvine (1985), however during the transitional periods we analyzed no persistent wind direction was observed. While winds certainly influence surface circulation, all of the wind records we examined were dominated by frequent wind events lasting 3-5 days with no persistent wind direction (see Figures 11 and 12 for examples). These highly variable wind conditions prohibit a simplified surface Ekman analysis that depends on steady winds. Faced with the challenge of variable winds, we focused our inquiry on one question: Is a low-frequency surface current response to changing winds detectable in synoptic records?

In conjunction with the surface current record, a high-resolution, nested wind model was used to explore this. Maps of complex correlation between surface currents and model wind stress at $10 \mathrm{~m}$ (Figure 10a and 10c) clearly show high correlation magnitudes ( 0.8 or higher) over most of the analysis region. Maps of mean veering angle (Figures 10b and 10d) are less clear, with surface currents to the right of the winds only at the center of the analysis region. While these low-frequency correlation results indicate some relationship between wind stress and surface currents, they are not rigorous evidence for wind-driven flow. A complicating factor in this assessment is the presence of the outflow plume. As shown in Figure 10, the complex correlation between the surface currents and the wind stress in the localized region of the outflow plume decreases from approximately 0.8 during the low outflow period to about 0.6 during the high outflow period. We conclude that wind events are not energetic or persistent enough to set up a detectable Ekman response.

Our study used synoptic surface currents and winds to establish that there is considerably more temporal and spatial variability in these fields at the Delaware Bay mouth than prior studies (based on traditional measurements from moorings, hydrographic cruises and remote wind reports) indicate. We contribute synoptic maps that characterize two known flow features (the outflow plume and the M2 tides) in much greater detail than earlier observational studies. We also identify one important new feature in the low-frequency circulation: a persistent cross-mouth flow toward the southwest.

To our knowledge this is the first tangible documentation of this cross-mouth flow. Similar cross-mouth flows have not been widely reported before. Thus it is important to identify the responsible dynamics. To this end it is obviously important to extend the radar coverage, both into the bay and along the shelf, to understand the spatial extent of this flow, and its connection with other nearshore currents. Carefully planned subsurface velocity measurements will also be important to assess its three-dimensional transport. 
${ }_{463}$ Numerical models driven by realistic winds will also be helpful. Deeper understanding of the complex surface ${ }_{464}$ circulation at the Delaware Bay mouth, as well as many other coastal areas, will require analyses of long time series of synoptic surface winds and currents using tools like those employed here. 


\section{Acknowledgments}

This work was supported by the Delaware Sea Grant, the University of Delaware College of Earth, Ocean, and Environment, and the Mary A. S. Lighthipe endowment to the University of Delaware. The contribution of N. P. Barton to this work was performed under the auspices of the U.S. Department of Energy by Lawrence Livermore National Laboratory (LLNL) under contract DE-AC52-07NA27344 and funded, in part, by the LLNL Institutional Postdoc Program. Operation of the Delaware Bay HF radars is supported by the National Oceanic and Atmospheric Administration and the Mid-Atlantic Coastal Ocean Observing Regional Association. We thank M. Whitney for providing M2 tidal ellipse data from his Delaware Bay model, and for insightful discussions regarding comparisons with HF radar tidal fits. We thank J. Kirby for providing parallel computing resources for the WRF calculations. WRF input data for this study are from the Research Data Archive (RDA) which is maintained by the Computational and Information Systems Laboratory (CISL) at the National Center for Atmospheric Research (NCAR). NCAR is sponsored by the National Science Foundation (NSF). The original WRF input data are available from the RDA (http://dss.ucar.edu) in dataset number ds609.2. We also thank Rich Pawlowicz for providing the freely available M_MAP and T_TIDE Matlab toolboxes used here. Finally we are pleased to acknowledge insightful discussions with A. Münchow, F. Pimenta and Ana E. Rice.

\section{REFERENCES}

Ahmadov, R., Gerbig, C., Kretschmer, R., Koerner, S., Neininger, B., Dolman, A., Sarrat, C., 2007. Mesoscale covariance of transport and $\mathrm{CO}_{2}$ fluxes: Evidence from observations and simulations using the WRF-VPRM coupled atmosphere-biosphere model. J. Geophys. Res. 112, D22107.

Avicola, G., Huq, P., 2002. Scaling analysis for the interaction between a buoyant coastal current and the continental shelf: Experiments and observations. J. Phys. Oceanogr. 32 (11), 3233-3248.

Beckenbach, E., Washburn, L., 2004. Low-frequency waves in the Santa Barbara Channel observed by highfrequency radar. J. Geophys. Res. 109, 18.

Brink, K. H., Bane, J. M., Church, T. M., Fairall, C. W., Geernaert, G. L., Hammond, D. E., Henrichs, S. M., Martens, C. S., Nittrouer, C. A., Rogers, D. P., Roman, M. R., Roughgarden, J. D., Smith, R. L., Wright, L. D., Yoder, J. A., 1992. Coastal ocean processes: A science prospectus. Tech. rep., Woods Hole Oceanographic Institution, Woods Hole, Massachusetts.

Chapman, R. D., Shay, L. K., Graber, H. C., Edson, J. B., Karachintsev, A., Trump, C. L., Ross, D. B., 1997. 
On the accuracy of HF radar surface current measurements: Intercomparisons with ship-based sensors. J. Geophys. Res. 102, 18737-18748.

Chen, F., Dudhia, J., 2001. Coupling an advanced land surface-hydrology model with the Penn State-NCAR MM5 modeling system. Part i: Model implementation and sensitivity. Mon. Weath. Rev. 129 (4), $569-585$.

Coulliette, C., Lekien, F., Paduan, J. D., Haller, G., Marsden, J. E., 2007. Optimal pollution mitigation in Monterey Bay based on coastal radar data and nonlinear dynamics. Environ. Sci. Technol. 41, 6562-6572.

Darby, L., Mckeen, S., Senff, C., White, A., Banta, R., Post, M., Brewer, W., Marchbanks, R., Alvarez, R., Peckham, S., Mao, H., Talbot, R., 2007. Ozone differences between near-coastal and offshore sites in New England: Role of meteorology. J. Geophys. Res. 112, D16S91.

Dudhia, J., 1989. Numerical study of convection observed during the winter monsoon experiment using a mesoscale two-dimensional model. J. Atmos. Sci. 46 (20), 3077-3107.

Ek, M., Mitchell, K., Lin, Y., Rogers, E., Grunmann, P., Koren, V., Gayno, G., Tarpley, J., 2003. Implementation of Noah land surface model advances in the National Centers for Environmental Prediction operational mesoscale Eta model. J. Geophys. Res. 108, 8851.

Garvine, R. W., 1985. A simple model of estuarine subtidal fluctuations forced by local and remote wind stress. J. Geophys. Res. 90, 1945-1948.

Garvine, R. W., 1991. Subtidal frequency estuary-shelf interaction: Observations near Delaware Bay. J. Geophys. Res. 96, 7049-7064.

Holt, T., Niyogi, D., Chen, F., Manning, K., Lemone, M., Qureshi, A., 2006. Effect of land-atmosphere interactions on the IHOP 24-25 may 2002 convection case. Mon. Weath. Rev. 134 (1), 113-133.

Hong, S. Y., Noh, Y., Dudhia, J., 2006. A new vertical diffusion package with an explicit treatment of entrainment processes. Mon. Weath. Rev. 134 (9), 2318 - 2341.

Janzen, C. D., 2000. Wind forced dynamics of an estuary-shelf regime: Delaware Bay and the adjacent inner shelf. Ph.D. thesis, University of Delaware.

Kabat, P., Claussen, M., Dirmeyer, P. A., Gash, J. H. C., Bravo de Guenni, L., Meybeck, M., Pielke Sr., R. A., Vorosmarty, C. J., Hutjes, R. W. A., Lutkemeier, S. (Eds.), 2004. Vegetation, Water, Humans and the Climate. Springer, pp. 375-413.

Kundu, P. K., 1976. Ekman veering observed near the ocean bottom. J. Phys. Oceanogr. 6, $238-242$.

Lipa, B. J., Barrick, D., 1983. Least-squares methods for the extraction of surface currents from CODAR crossed-loop data: Application at ARSLOE. IEEE J. Ocean. Eng. 8 (4), 226-253. 
Lipphardt Jr., B. L., Small, D., Kirwan Jr., A. D., Wiggins, S., Ide, K., Grosch, C. E., Paduan, J. D., 2006. Synoptic Lagrangian maps: Application to surface transport in Monterey Bay. J. Mar. Res. 64, 221-247.

McPherson, R. D., 1970. A numerical study of the effect of a coastal irregularity on the sea breeze. Jour. Appl. Met. 9 (5), $767-777$.

Mlawer, E. J., Taubman, S. J., Brown, P. D., Iacono, M. J., Clough, S. A., 1997. Radiative transfer for inhomogeneous atmospheres: RRTM, a validated correlated-k model for the longwave. J. Geophys. Res. - Atmos. 102, 16663-16682.

Münchow, A., 1992. The formation of a buoyancy driven coastal current. Ph.D. thesis, University of Delaware.

Münchow, A., Garvine, R. W., 1993. Buoyancy and wind forcing of a coastal current. J. Mar. Res. 51 (2), 293-322.

Münchow, A., Masse, A. K., Garvine, R. W., 1992. Astronomical and nonlinear tidal currents in a coupled estuary shelf system. Cont. Shelf Res. 12, 471-498.

Nolan, D., Zhang, C., Chen, S., 2007. Dynamics of the shallow meridional circulation around intertropical convergence zones. J. Atmos. Sci. 64 (7), 2262-2285.

Ohashi, Y., Kida, H., 2002. Local circulations developed in the vicinity of both coastal and inland urban areas: A numerical study with a mesoscale atmospheric model. J. Applied Met. 41 (1), 30-45.

Ohlmann, C., White, P., Washburn, L., Terrill, E., Emery, B., Otero, M., 2007. Interpretation of coastal HF radar-derived surface currents with high-resolution drifter data. Jour. Atmos. Ocean Tech. 24, 666-680.

Paduan, J., Graber, H., 1997. Introduction to high-frequency radar: Reality and myth. Oceanography 10, 36-39.

Paduan, J. D., Kim, K. C., Cook, M. S., Chavez, F. P., 2006. Calibration and validation of direction-finding high-frequency radar ocean surface current observations. IEEE J. Ocean. Eng. 31 (4), 862-875.

Paduan, J. D., Rosenfeld, L. K., 1996. Remotely sensed surface currents in Monterey Bay from shore-based HF radar (Coastal Ocean Dynamics Application Radar). J. Geophys. Res. 101, 20669-20686.

Pan, H. L., Mahrt, L., 1987. Interaction between soil hydrology and boundary-layer development. Bound. Layer Met. 38 (1-2), 185-202.

Pape, E. H., Garvine, R. W., 1982. The subtidal circulation in Delaware Bay and adjacent shelf waters. J. Geophys. Res. 87, 7955-7970.

Pawlowicz, R., Beardsley, B., Lentz, S., 2002. Classical tidal harmonic analysis including error estimates in MATLAB using T_TIDE. Computers and Geosci. 28, 929-937. 
Pielke, R. A., 2001. Influence of the spatial distribution of vegetation and soils on the prediction of cumulus convective rainfall. Rev. of Geophys. 39 (2), 151-177.

Shay, L. K., Cook, T. M., Hallock, Z. R., Haus, B. K., Graber, H. C., Martinez, J., 2001. The strength of the $\mathrm{m}_{2}$ tide at the Chesapeake Bay mouth. J. Phys. Oceanogr. 31, 427-449.

Skamarock, W. C., Klemp, J. B., Dudhai, J., Gill, D. O., Barker, D. M., Wang, W., Powers, J. G., 2007. A description of the Advanced Research WRF Version 2.

URL http://www.mmm.ucar.edu/wrf/users/docs/arw_v2.pdf

Skarke, A., Lipphardt Jr., B. L., Muscarella, P., Wong, K.-C., Trembanis, A., Badiey, M., 2008. Comparison of HF radar and ADCP surface currents at the Delaware Bay mouth. In: Proceedings of the IEEE/OES/CMTC Ninth Working Conference on Current Measurement Technology.

Thompson, W. T., Holt, T., Pullen, J., 2007. Investigation of a sea breeze front in an urban environments. Quart. Jour. of the Royal Met. Soc. 133 (624), 579-594.

Wang, W., Barker, D., Bray, J., Bruyere, C., Duda, M., Dudhia, J., D., G., J., M., 2007. User's guide for Advanced Research WRF (ARW) modeling system version 2.2.

URL http://www.mmm.ucar.edu/wrf/users

Whitney, M. M., 2003. Simulating the Delaware Coastal Current. Ph.D. thesis, University of Delaware.

Whitney, M. M., Garvine, R. W., 2006. Simulating the Delaware Bay buoyant outflow: Comparison with observations. J. Phys. Oceanogr. 36 (1), 3-21.

Whitney, M. M., Garvine, R. W., 2008. Estimating tidal current amplitudes outside estuaries and characterizing the zone of estuarine tidal influence. Cont. Shelf Res. 28 (3), 380-390.

Wong, K.-C., 1999. The wind driven currents on the Middle Atlantic Bight inner shelf. Cont. Shelf Res. $19(6), 757-773$.

Wong, K.-C., Moses-Hall, J. E., 1998. The tidal and subtidal variations in the transverse salinity and current distributions across a coastal plain estuary. J. Mar. Res. 56, 489-517.

Wong, K.-C., Münchow, A., 1995. Buoyancy forced interaction between estuary and inner shelf: observation. Cont. Shelf Res. 15, 59-88. 


\section{List of Figures}

1 (a) Example WRF model winds. Every third wind vector is shown, for clarity. The green box shows the limits of the geographic region shown in (b). (b) Example HF radar surface currents at the Delaware Bay mouth. Color contours show bottom topography (in m) and the two radar antenna locations are shown as red circles. The red point labeled as 'A' near the center of the radar footprint shows the location where the wind-current comparisons shown in Figure 9 were made. Both panels show conditions for 1000 UT, 1 October 2007. . . . . . . 23

2 Color contours of temporal coverage (in percent) of HF radar measurements for the period 1 October 2007 through 31 May 2008. The 250 grid locations with a minimum of $80 \%$ coverage are shown as black circles. At these locations, mean velocity vectors (black) for the entire

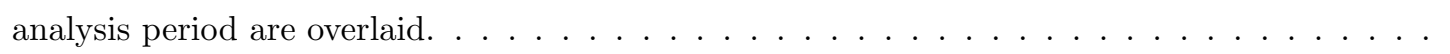

3 Two inner domain nests (yellow boxes, numbered 2 and 3) used for the Delaware Bay WRF model. Six wind measurement stations on or near land (white circles) and two stations over water (red circles) were used to assess the WRF model as part of this study. The region outside the bay mouth that is the focus for this study is shown as a green box. The WRF model outer nest (not shown) extends from just south of Cape Hatteras, NC northward to

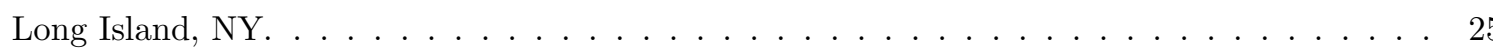

$4 \quad$ M2 tidal ellipses for the period 1 October 2007 through 31 May 2008. For clarity, only ellipses at every second analysis location are shown. Historical ellipses reported by Münchow et al. (1992) are shown in black. . . . . . . . . . . . . . . . . . . . . . .

5 Differences between Whitney and Garvine (2008) model depth-averaged M2 $r_{a}$ and nearsurface HF radar M2 $r_{a}$ at all radar grid locations with a minimum of $80 \%$ coverage in time. Model values were linearly interpolated to the radar grid. Circle colors represent model $r_{a}$

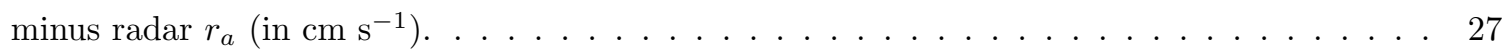

6 Profiles of M2 $r_{a}$ along a line perpendicular to the line across the Delaware Bay mouth (black line shown in Figure 5) from the Whitney and Garvine (2008) model (depth-averaged, in red) and from HF radar tidal fits (near-surface, in blue). All values are in $\mathrm{cm} \mathrm{s}^{-1}$ and were spatially interpolated at $1 \mathrm{~km}$ intervals along the profile line. . . . . . . . . . . . 28

7 Color contours of percent variance explained by the five constituent tidal fit for the period 1 October 2007 through 31 May $2008 . \ldots \ldots \ldots$

8 Time series of Delaware River flow $\left(\mathrm{m}^{3} \mathrm{~s}^{-1}\right)$ measured near Trenton, New Jersey for October 2007 through May 2008. The low outflow (October-November 2007) and high outflow (MarchApril 2008) periods are highlighted in grey. . . . . . . . . . . . . . . . . . 30

9 Mean HF radar surface currents (black vectors) overlaid on color contours of the ratio of the mean current speed to the magnitude of the standard deviation for (a) the low outflow period,

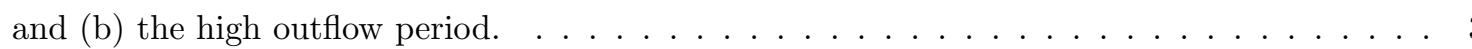


10 Maps of $\sigma_{m a g}$ and $\sigma_{\text {phase }}$ (degrees) for correlations between surface currents and WRF $10 \mathrm{~m}$ wind stress. Surface current and wind stress vector time series were 40-hour low-pass filtered. Negative $\sigma_{\text {phase }}$ values indicate currents to the right of the winds. (a) $\sigma_{\text {mag }}$ for the low outflow period ; (b) $\sigma_{\text {phase }}$ for the low outflow period ; (c) $\sigma_{\text {mag }}$ for the high outflow period ; (d) $\sigma_{\text {phase }}$ for the high outflow period. . . . . . . . . . . . . . . . . . . . . . . 32

11 Wind and surface current time series at point 'A' in Figure 1 for the low outflow period: (a) 40-hour low-pass filtered WRF winds at $10 \mathrm{~m}$; (b) 40-hour low-pass filtered surface currents from radar; (c) Direction difference in degrees (currents minus winds). Points shown in red

12 Wind and surface current time series at point 'A' in Figure 1 for the high outflow period: (a) 40-hour low-pass filtered WRF winds at $10 \mathrm{~m}$; (b) 40-hour low-pass filtered surface currents from radar; (c) Direction difference in degrees (currents minus winds). Points shown in red are for times when the current was to the right of the wind. . . . . . . . . . . . . 34 

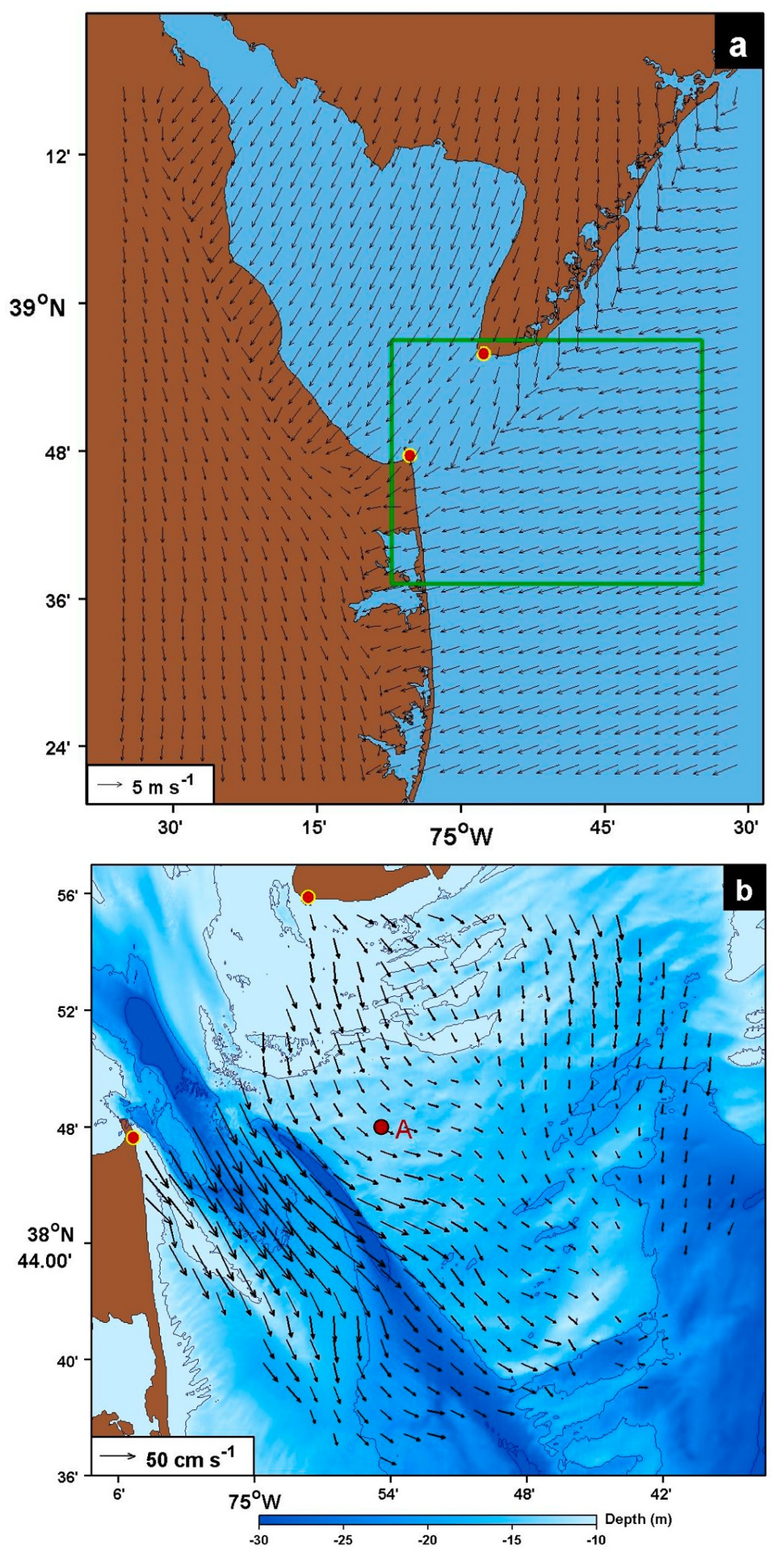

Figure 1: (a) Example WRF model winds. Every third wind vector is shown, for clarity. The green box shows the limits of the geographic region shown in (b). (b) Example HF radar surface currents at the Delaware Bay mouth. Color contours show bottom topography (in $\mathrm{m}$ ) and the two radar antenna locations are shown as red circles. The red point labeled as 'A' near the center of the radar footprint shows the location where the wind-current comparisons shown in Figure 9 were made. Both panels show conditions for $1000 \mathrm{UT}, 1$ October 2007. 


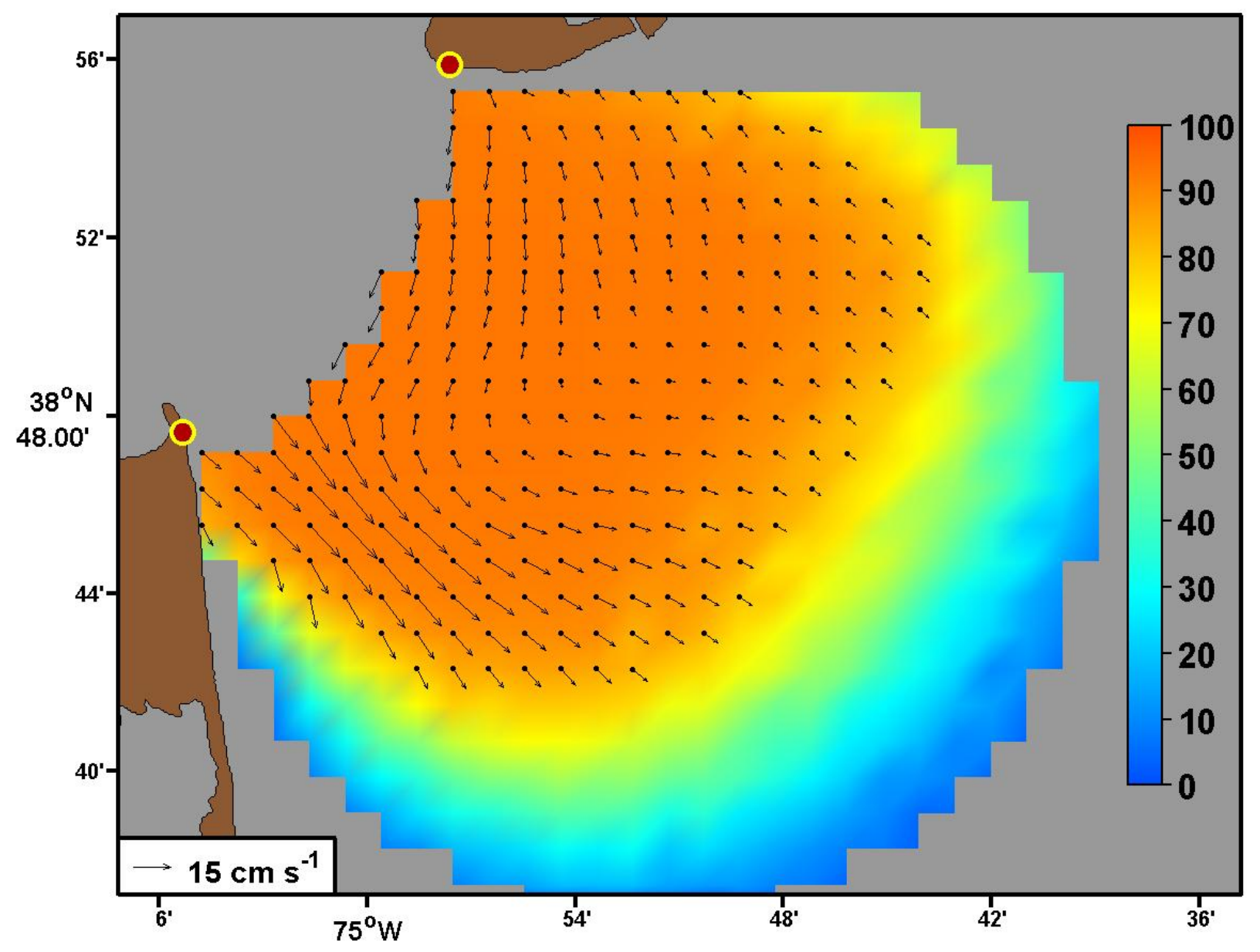

Figure 2: Color contours of temporal coverage (in percent) of HF radar measurements for the period 1 October 2007 through 31 May 2008. The 250 grid locations with a minimum of $80 \%$ coverage are shown as black circles. At these locations, mean velocity vectors (black) for the entire analysis period are overlaid. 


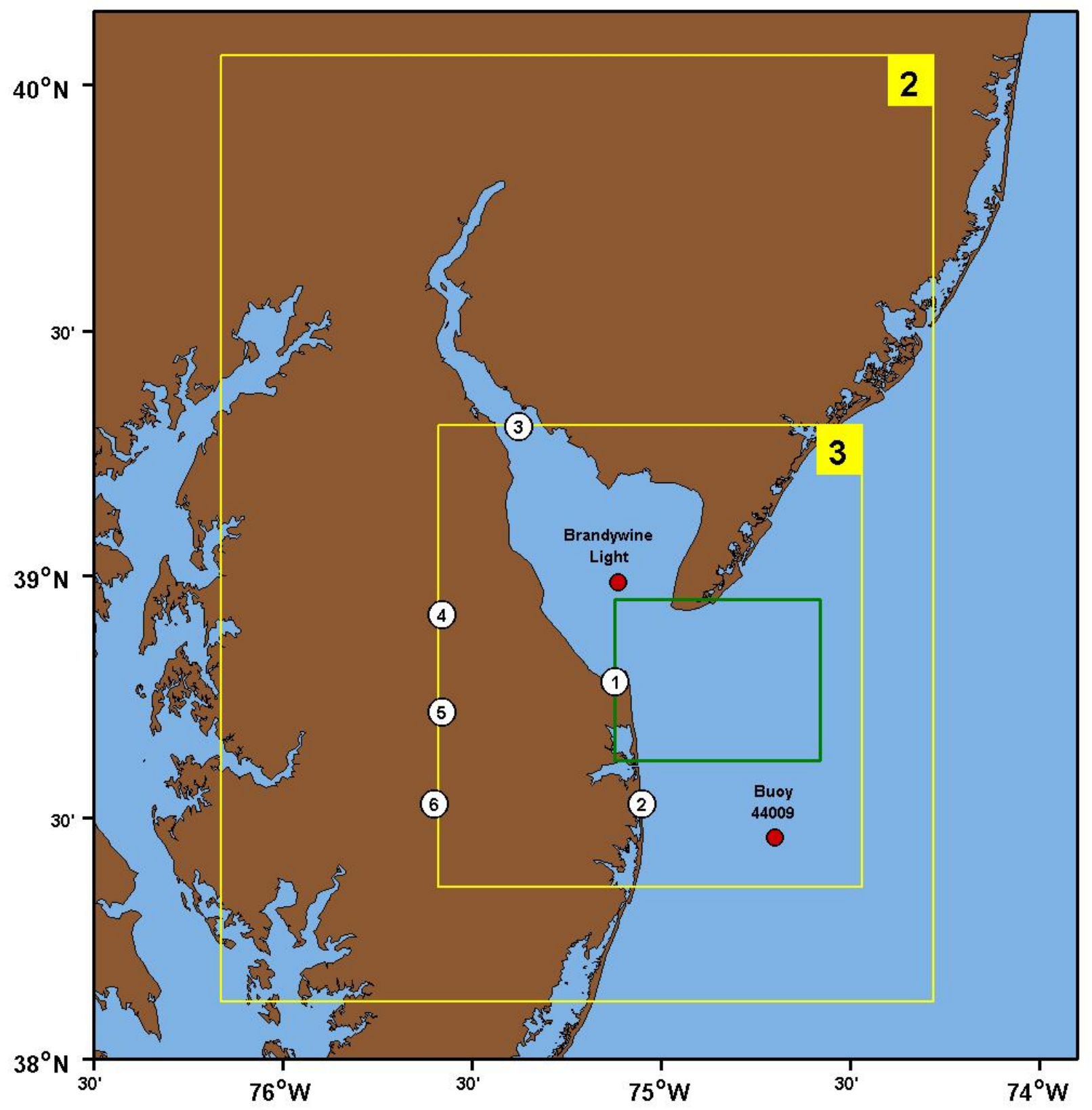

Figure 3: Two inner domain nests (yellow boxes, numbered 2 and 3) used for the Delaware Bay WRF model. Six wind measurement stations on or near land (white circles) and two stations over water (red circles) were used to assess the WRF model as part of this study. The region outside the bay mouth that is the focus for this study is shown as a green box. The WRF model outer nest (not shown) extends from just south of Cape Hatteras, NC northward to Long Island, NY. 


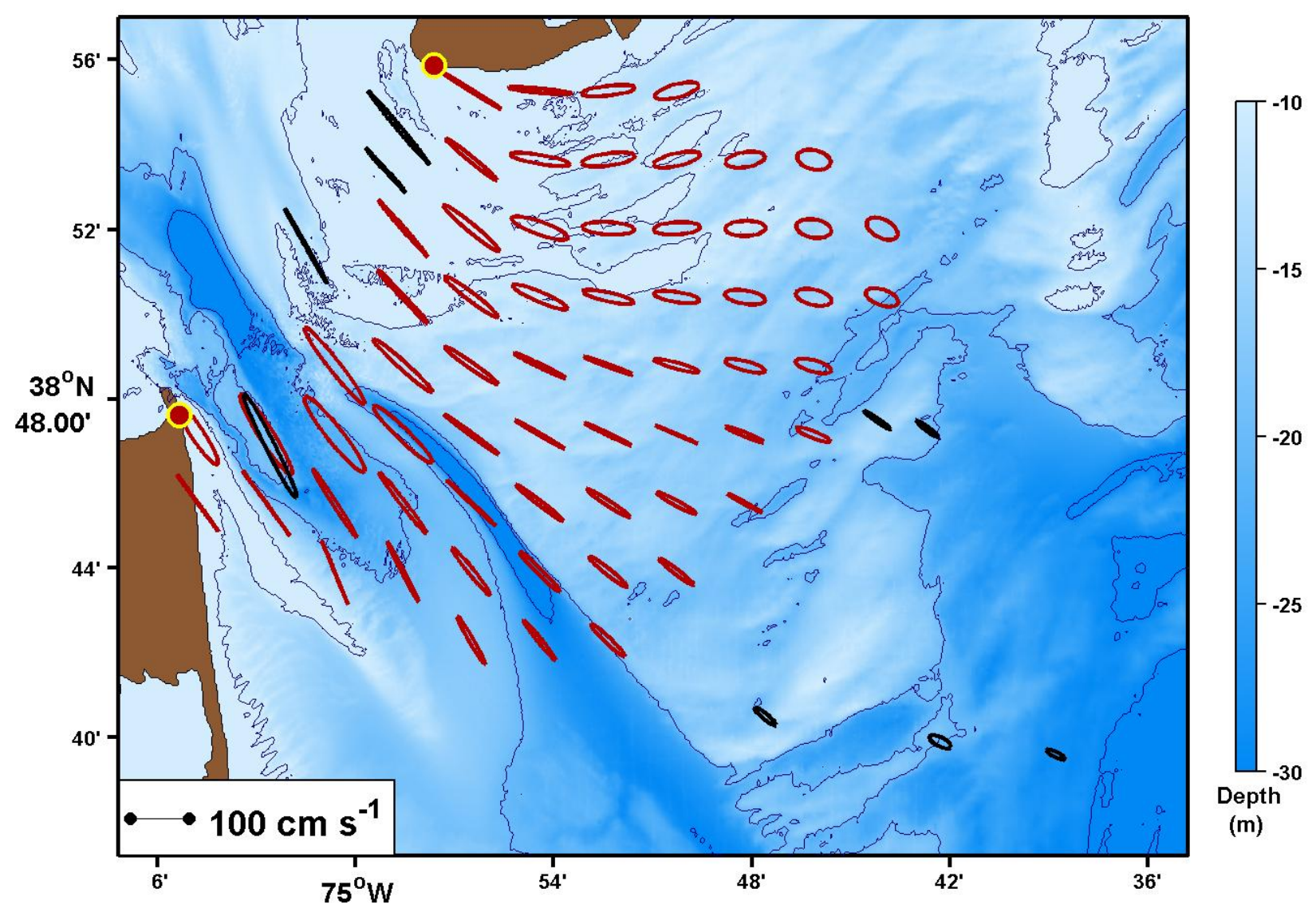

Figure 4: M2 tidal ellipses for the period 1 October 2007 through 31 May 2008. For clarity, only ellipses at every second analysis location are shown. Historical ellipses reported by Münchow et al. (1992) are shown in black. 


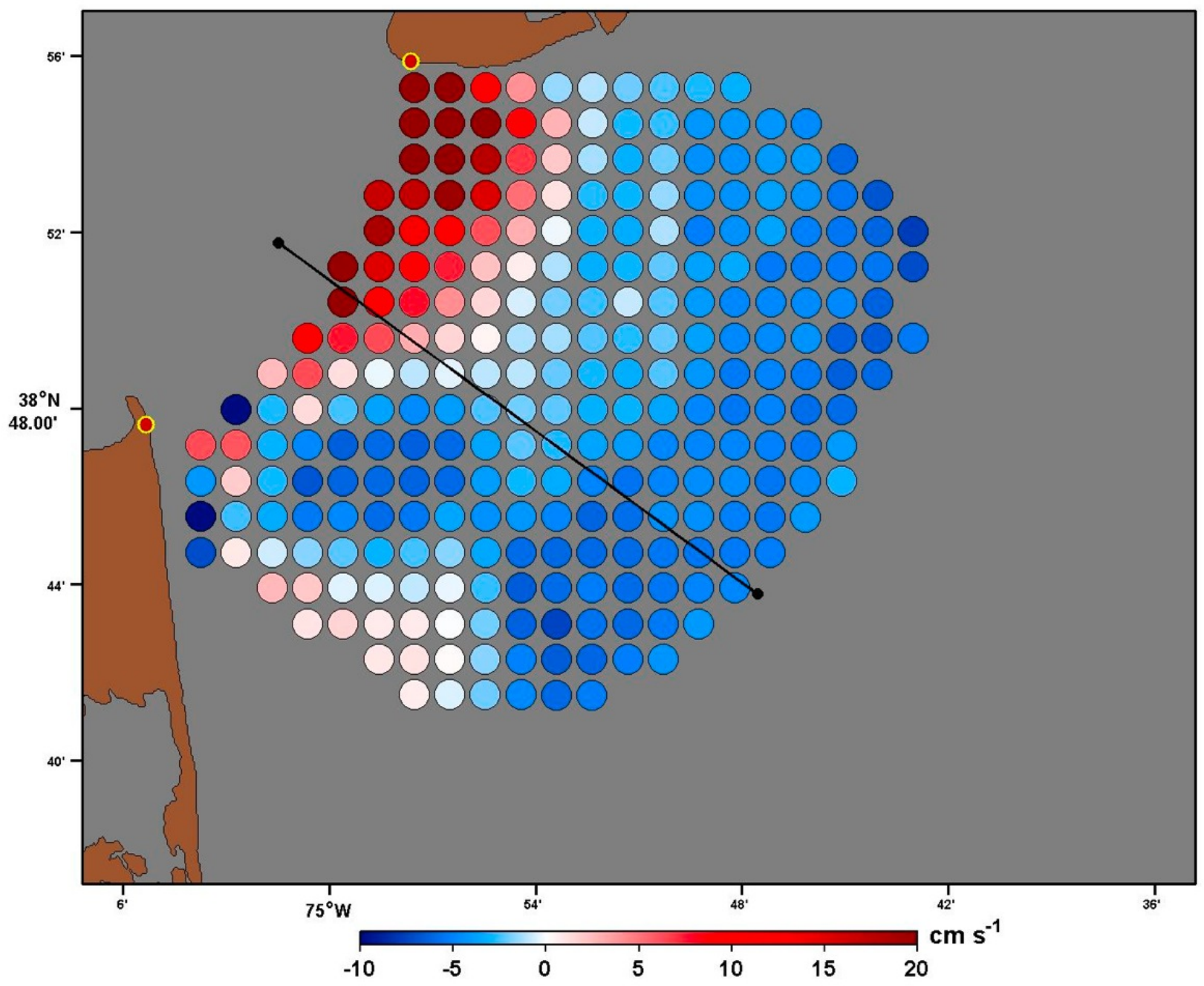

Figure 5: Differences between Whitney and Garvine (2008) model depth-averaged M2 $r_{a}$ and near-surface $\mathrm{HF}$ radar M2 $r_{a}$ at all radar grid locations with a minimum of $80 \%$ coverage in time. Model values were linearly interpolated to the radar grid. Circle colors represent model $r_{a}$ minus radar $r_{a}\left(\right.$ in $\left.\mathrm{cm} \mathrm{s}^{-1}\right)$. 


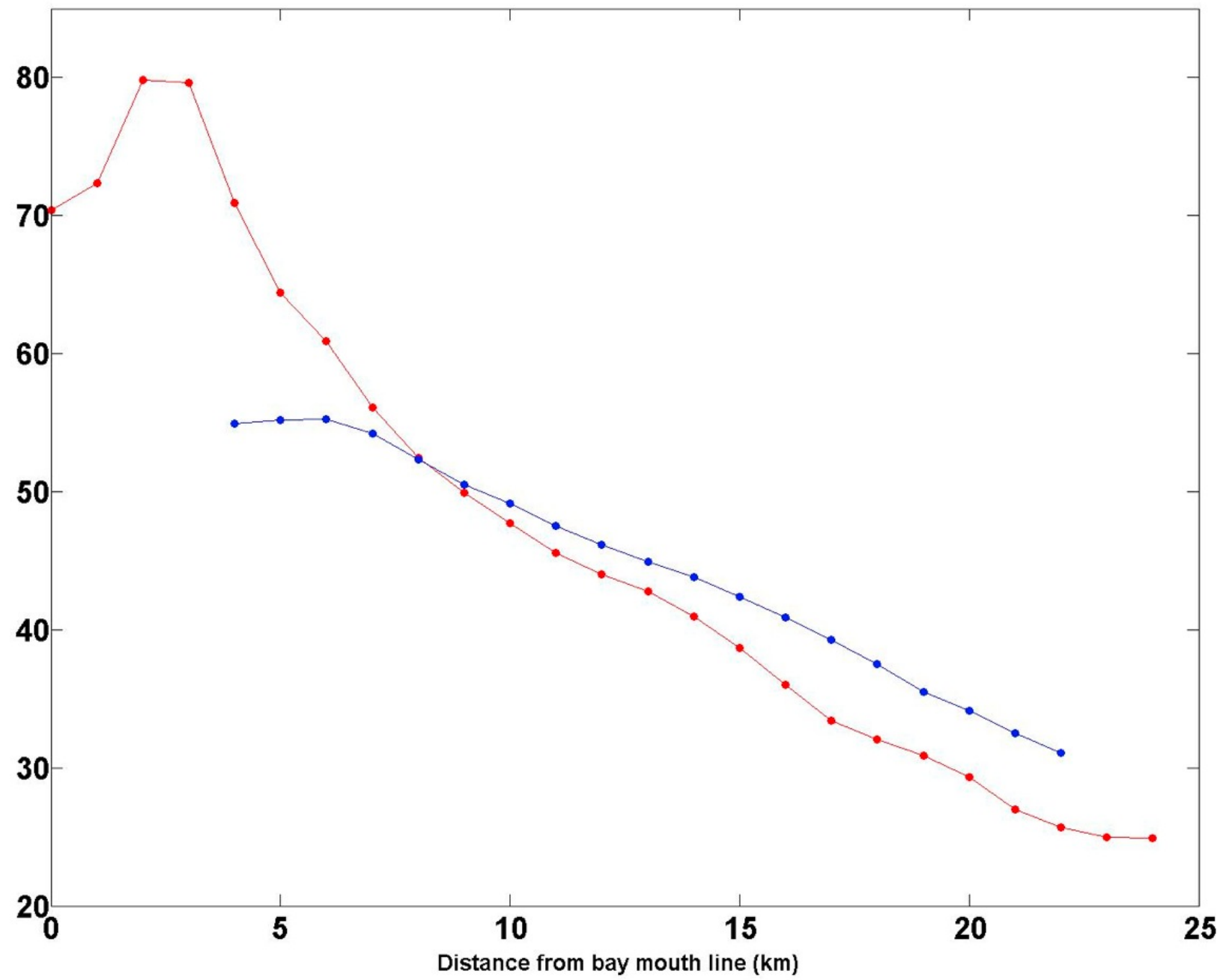

Figure 6: Profiles of M2 $r_{a}$ along a line perpendicular to the line across the Delaware Bay mouth (black line shown in Figure 5) from the Whitney and Garvine (2008) model (depth-averaged, in red) and from HF radar tidal fits (near-surface, in blue). All values are in $\mathrm{cm} \mathrm{s}^{-1}$ and were spatially interpolated at $1 \mathrm{~km}$ intervals along the profile line. 


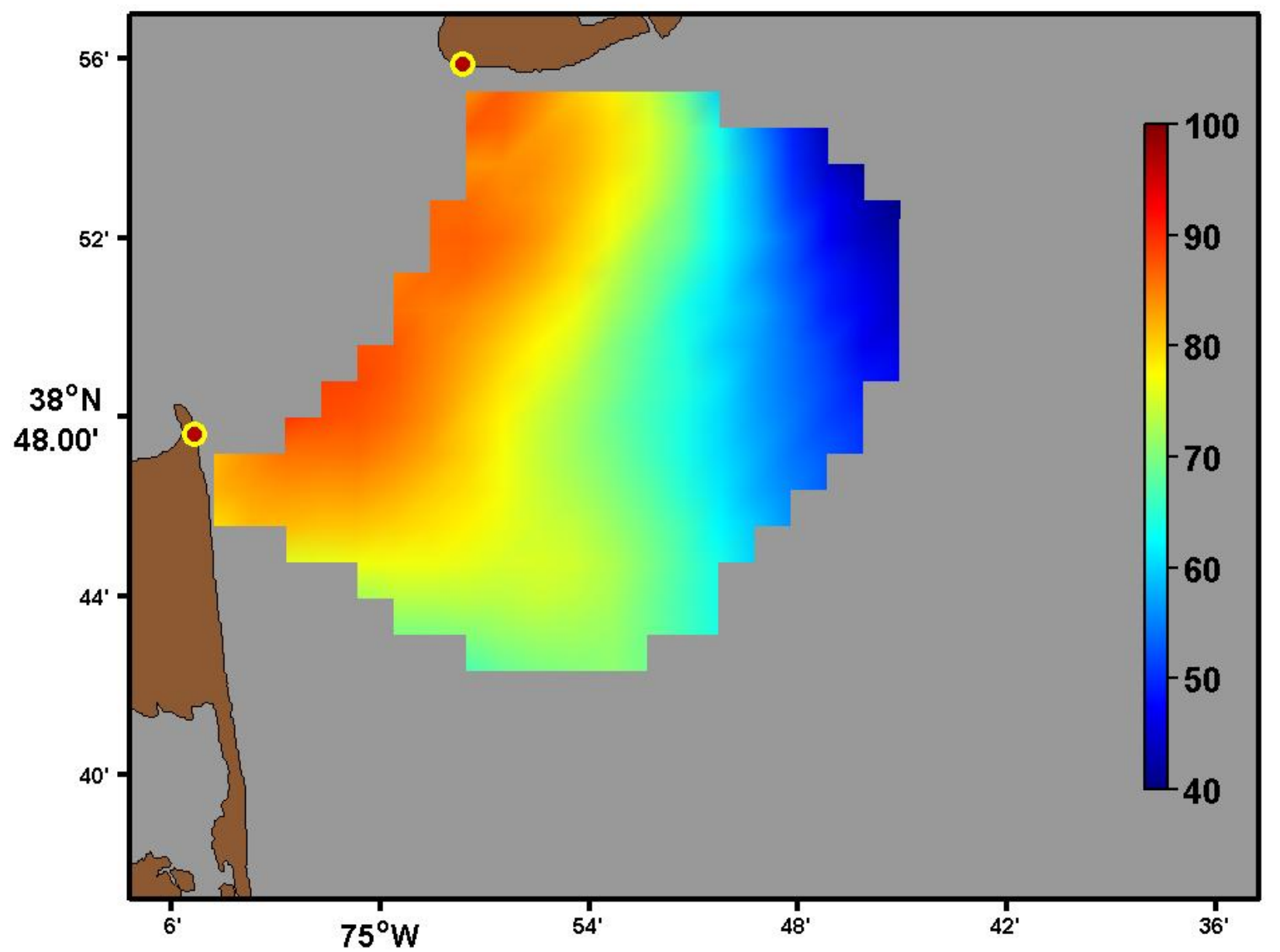

Figure 7: Color contours of percent variance explained by the five constituent tidal fit for the period 1 October 2007 through 31 May 2008. 


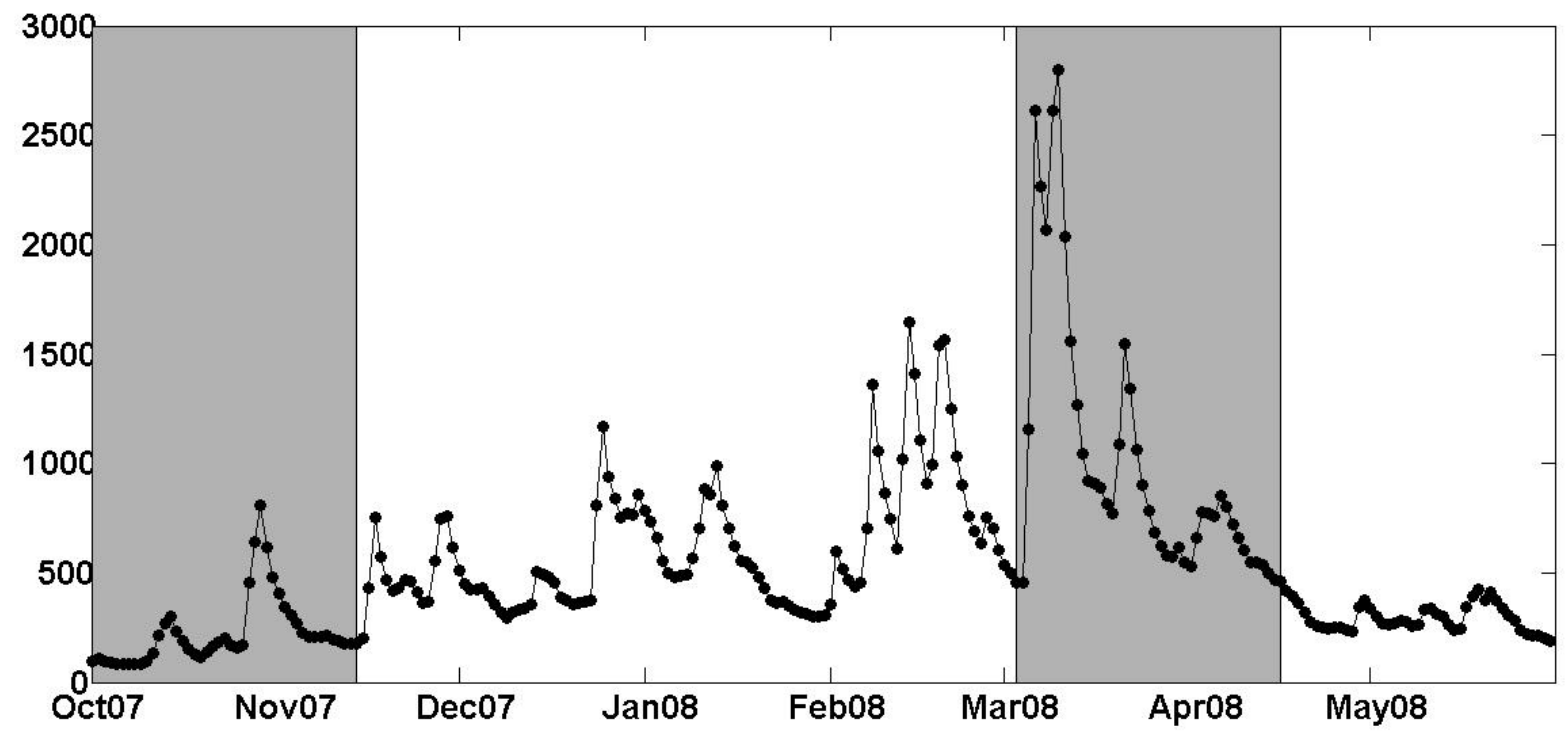

Figure 8: Time series of Delaware River flow $\left(\mathrm{m}^{3} \mathrm{~s}^{-1}\right)$ measured near Trenton, New Jersey for October 2007 through May 2008. The low outflow (October-November 2007) and high outflow (March-April 2008) periods are highlighted in grey. 

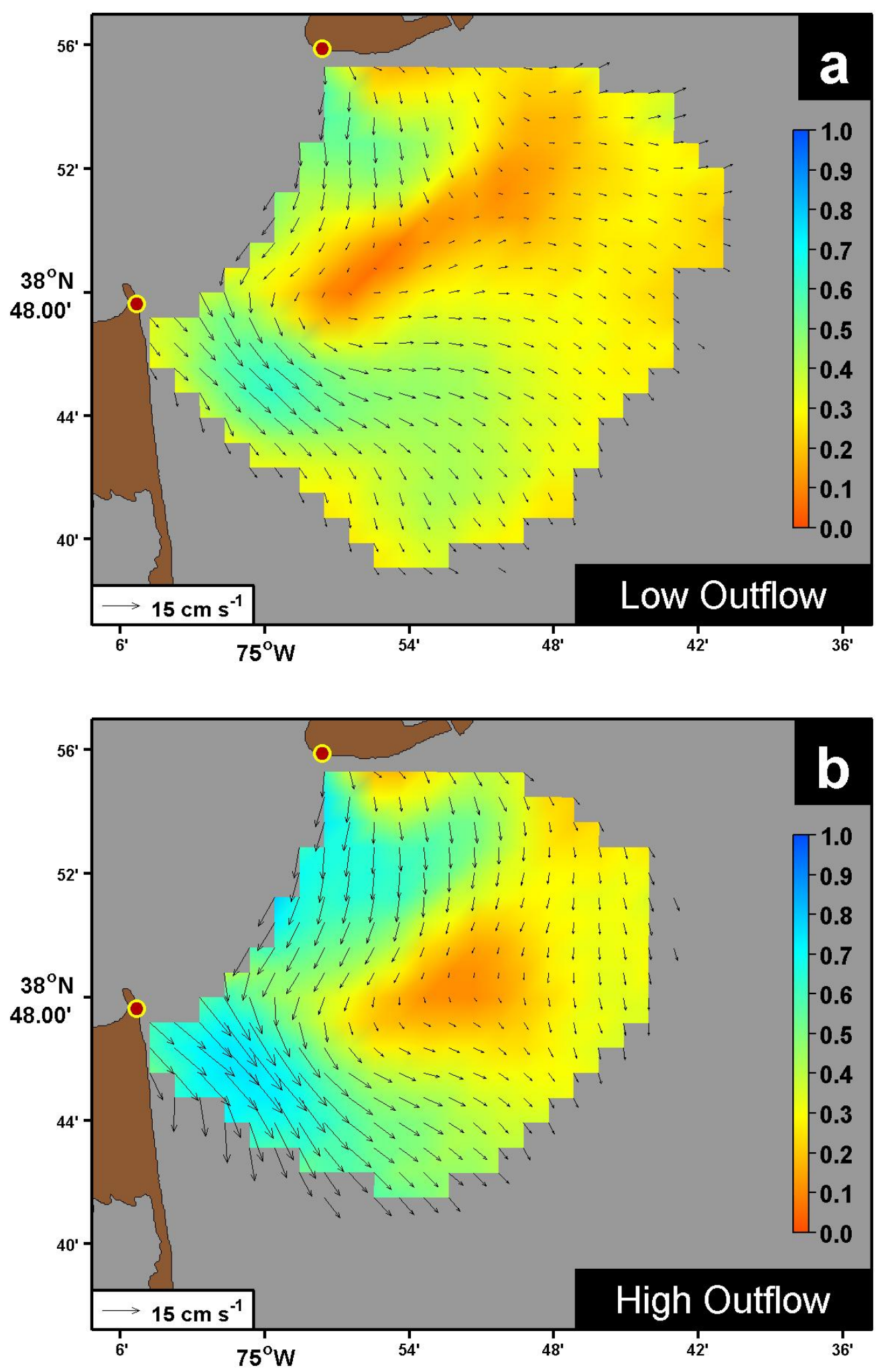

Figure 9: Mean HF radar surface currents (black vectors) overlaid on color contours of the ratio of the mean current speed to the magnitude of the standard deviation for (a) the low outflow period, and (b) the high outflow period. 

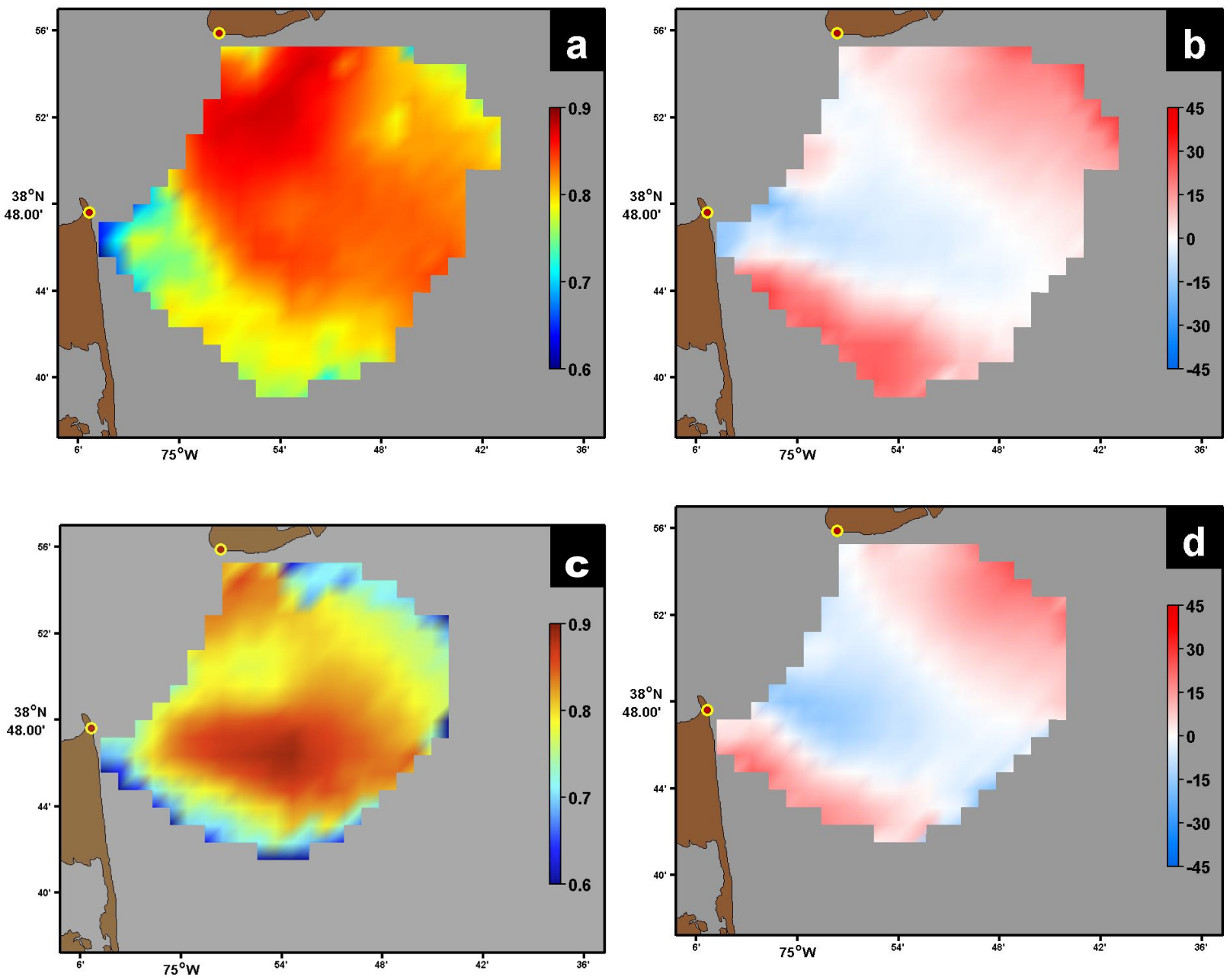

Figure 10: Maps of $\sigma_{\text {mag }}$ and $\sigma_{\text {phase }}$ (degrees) for correlations between surface currents and WRF $10 \mathrm{~m}$ wind stress. Surface current and wind stress vector time series were 40-hour low-pass filtered. Negative $\sigma_{\text {phase }}$ values indicate currents to the right of the winds. (a) $\sigma_{\text {mag }}$ for the low outflow period ; (b) $\sigma_{\text {phase }}$ for the low outflow period ; (c) $\sigma_{m a g}$ for the high outflow period ; (d) $\sigma_{\text {phase }}$ for the high outflow period. 


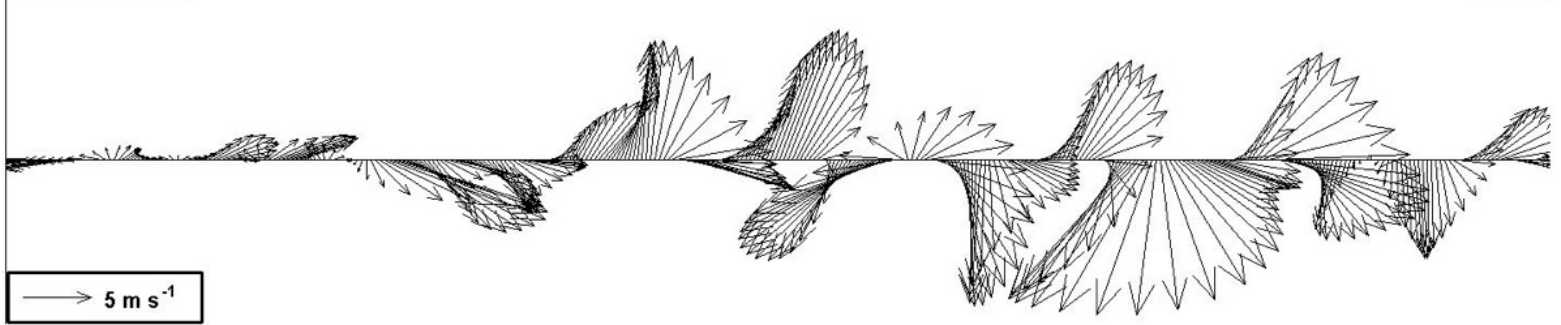

Currents

b

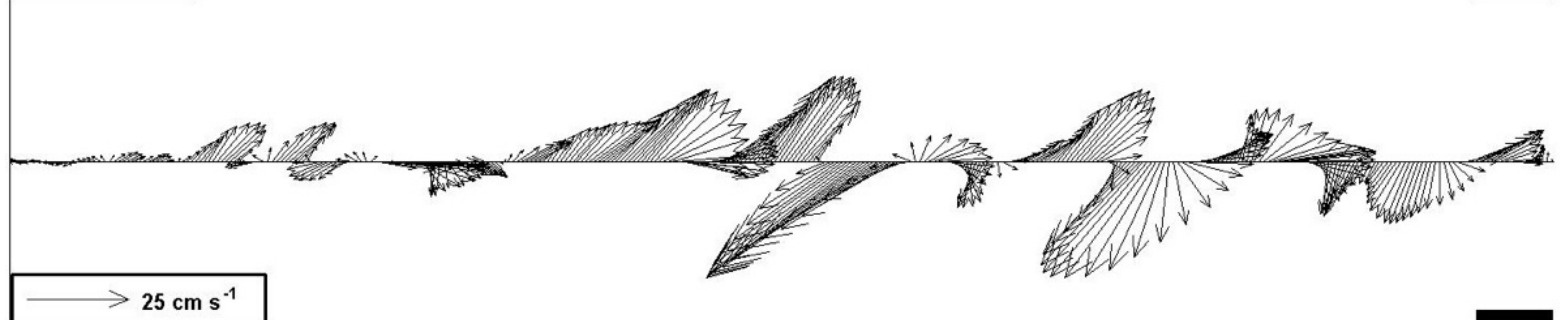

$25 \mathrm{~cm} \mathrm{~s}^{-1}$

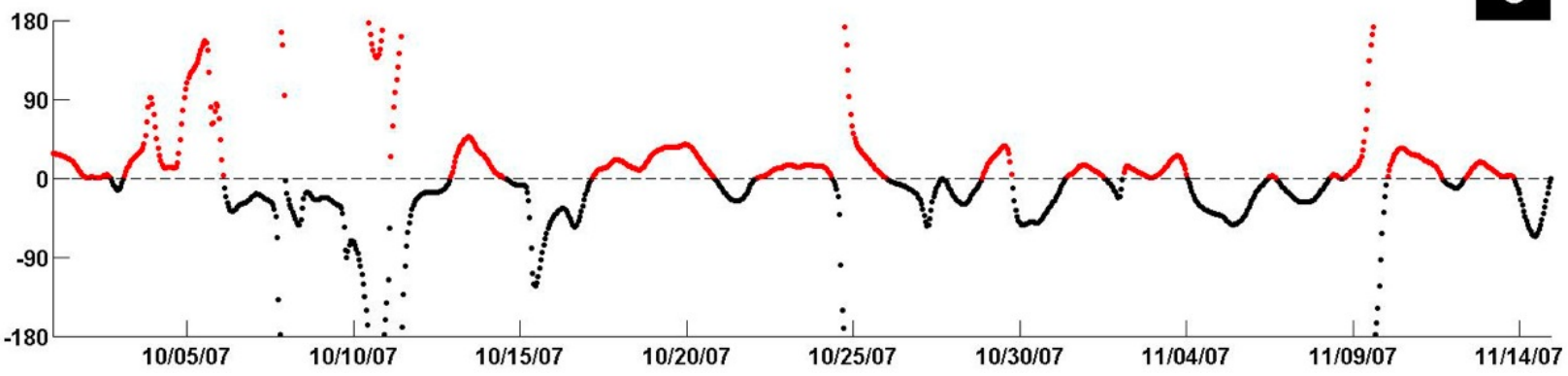

Figure 11: Wind and surface current time series at point 'A' in Figure 1 for the low outflow period: (a) 40-hour low-pass filtered WRF winds at $10 \mathrm{~m}$; (b) 40-hour low-pass filtered surface currents from radar; (c) Direction difference in degrees (currents minus winds). Points shown in red are for times when the current was to the right of the wind. 


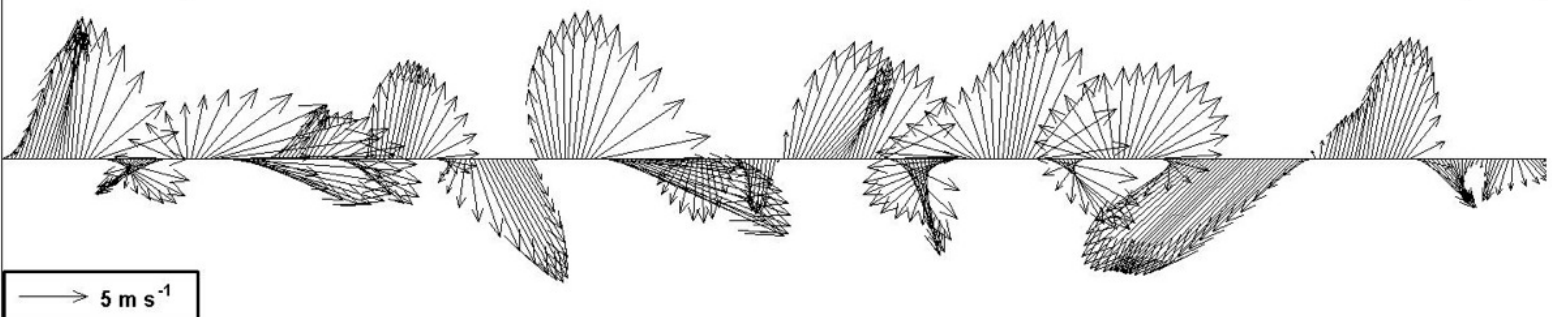

Currents

b

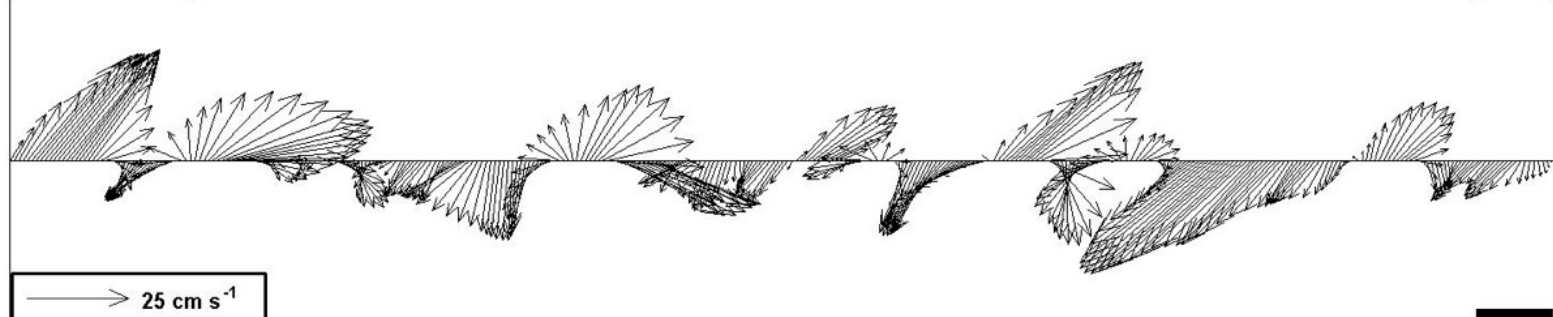

$>25 \mathrm{~cm} \mathrm{~s}^{-1}$

C

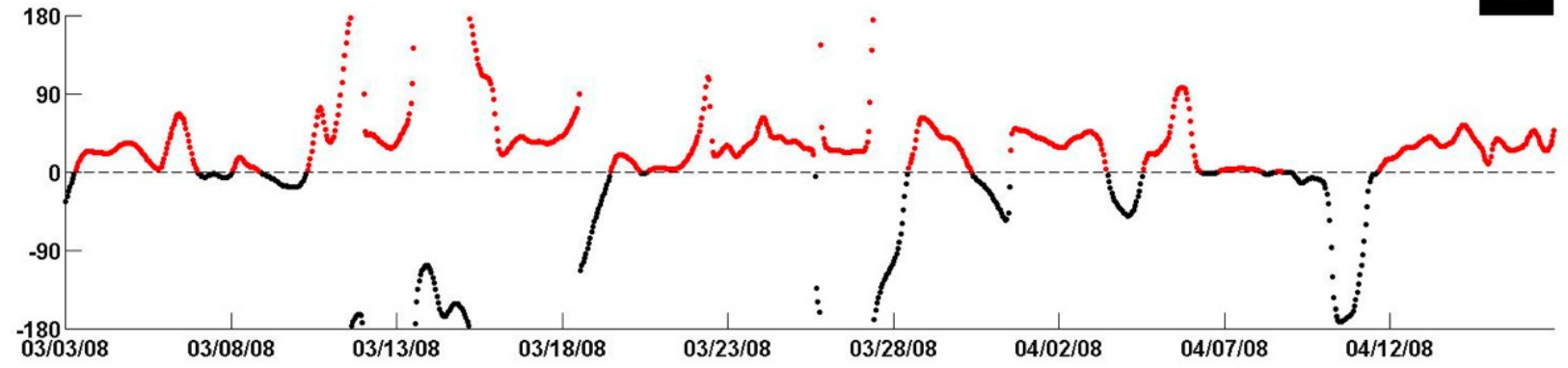

Figure 12: Wind and surface current time series at point 'A' in Figure 1 for the high outflow period: (a) 40-hour low-pass filtered WRF winds at $10 \mathrm{~m}$; (b) 40-hour low-pass filtered surface currents from radar; (c) Direction difference in degrees (currents minus winds). Points shown in red are for times when the current was to the right of the wind. 


\section{List of Tables}

1 Statistics of comparisons between observed and WRF model winds at eight stations . . . . 36

2 Period (hrs), $\mathcal{M}\left(\mathrm{cm} \mathrm{s}^{-1}\right)$, and $S N R$ statistics for tide fits from HF radar measurements . . . 37 
Table 1: Statistics of comparisons between observed and WRF model winds at eight stations

\begin{tabular}{|c|c|c|c|c|c|}
\hline Period & Station & $\sigma_{m a g}$ & $\sigma_{\text {phase }}$ & $|\vec{v}|_{r m s}$ & $\Delta(u, v)_{r m s}$ \\
\hline \multirow{8}{*}{ Low outflow } & Brandywine & 0.88 & 1.30 & 7.50 & $\begin{array}{ll}u & 2.65 \\
v & 2.63\end{array}$ \\
\hline & Buoy 44009 & 0.89 & 7.71 & 7.23 & $\begin{array}{ll}u & 2.75 \\
v & 2.38\end{array}$ \\
\hline & 1 & 0.82 & 18.37 & 5.56 & $\begin{array}{ll}u & 2.98 \\
v & 2.83\end{array}$ \\
\hline & 2 & 0.83 & 4.72 & 3.26 & $\begin{array}{ll}u & 2.39 \\
v & 2.39\end{array}$ \\
\hline & 3 & 0.82 & -1.04 & 5.41 & $\begin{array}{ll}u & 2.47 \\
v & 2.28\end{array}$ \\
\hline & 4 & 0.77 & -1.31 & 2.64 & $\begin{array}{ll}u & 1.86 \\
v & 1.63\end{array}$ \\
\hline & 5 & 0.79 & 0.91 & 2.98 & $\begin{array}{ll}u & 1.71 \\
v & 1.67\end{array}$ \\
\hline & 6 & 0.75 & 16.91 & 3.27 & $\begin{array}{ll}u & 1.84 \\
v & 1.97\end{array}$ \\
\hline \multirow{7}{*}{ High outflow } & Buoy 44009 & 0.91 & 4.21 & 8.06 & $\begin{array}{ll}u & 2.57 \\
v & 2.69\end{array}$ \\
\hline & 1 & 0.87 & 21.69 & 6.65 & $\begin{array}{ll}u & 2.97 \\
v & 3.53\end{array}$ \\
\hline & 2 & 0.86 & 6.42 & 4.33 & $\begin{array}{ll}u & 2.25 \\
v & 3.11\end{array}$ \\
\hline & 3 & 0.85 & -2.26 & 6.94 & $\begin{array}{ll}u & 2.77 \\
v & 2.65\end{array}$ \\
\hline & 4 & 0.83 & 0.79 & 4.04 & $\begin{array}{ll}u & 2.13 \\
v & 2.07\end{array}$ \\
\hline & 5 & 0.85 & 2.05 & 4.21 & $\begin{array}{ll}u & 1.91 \\
v & 2.09\end{array}$ \\
\hline & 6 & 0.85 & 17.11 & 5.38 & $\begin{array}{ll}u & 2.25 \\
v & 2.29\end{array}$ \\
\hline
\end{tabular}


Table 2: Period (hrs), $\mathcal{M}\left(\mathrm{cm} \mathrm{s}^{-1}\right)$, and $S N R$ statistics for tide fits from HF radar measurements

\begin{tabular}{rrrrrrrrrr}
\hline & Period & $\mathcal{M}_{\min }$ & $\mathcal{M}_{\max }$ & $\overline{\mathcal{M}}$ & $\mathcal{M}_{S D}$ & $S N R_{\min }$ & $S N R_{\max }$ & $\overline{S N R}$ & $S N R_{S D}$ \\
\hline $\mathrm{M} 2$ & 12.42 & 28.52 & 84.01 & 43.77 & 10.77 & 986.55 & 5713.38 & 2297.70 & 881.07 \\
$\mathrm{~N} 2$ & 12.66 & 5.33 & 16.82 & 8.12 & 1.92 & 38.76 & 173.53 & 79.35 & 25.60 \\
$\mathrm{~S} 2$ & 12.00 & 5.55 & 15.19 & 8.02 & 1.67 & 38.03 & 199.09 & 81.79 & 23.10 \\
$\mathrm{~K} 1$ & 23.93 & 2.44 & 8.16 & 3.94 & 1.08 & 3.58 & 66.47 & 21.35 & 14.55 \\
$\mathrm{O} 1$ & 25.82 & 1.94 & 6.26 & 3.56 & 0.53 & 6.79 & 44.45 & 19.69 & 7.42 \\
\hline
\end{tabular}

